\title{
Labor Market Polarization Over the Business Cycle
}

\section{Citation}

Foote, Christopher L., and Richard W. Ryan. 2014. Labor Market Polarization over the Business Cycle. Working paper, Department of Economics, Harvard University.

\section{Permanent link}

http://nrs.harvard.edu/urn-3:HUL.InstRepos:25213041

\section{Terms of Use}

This article was downloaded from Harvard University's DASH repository, and is made available under the terms and conditions applicable to Other Posted Material, as set forth at http:// nrs.harvard.edu/urn-3:HUL.InstRepos:dash.current.terms-of-use\#LAA

\section{Share Your Story}

The Harvard community has made this article openly available.

Please share how this access benefits you. Submit a story.

\section{Accessibility}




\title{
Labor-Market Polarization Over the Business Cycle*
}

\author{
Christopher L. Foote ${ }^{\dagger} \quad$ Richard W. Ryan
}

June 3,2014

\begin{abstract}
Job losses in the Great Recession were concentrated among middle-skill workers, the same group that has suffered the most over the long-run from automation and international trade. How might long-run occupational polarization be related to cyclical changes in middle-skill employment? We find that middle-skill jobs have traditionally been more cyclical than other jobs, in part because of the volatile industries that tend to employ middle-skill workers. Also, unemployed middle-skill workers appear to have few attractive or feasible employment alternatives outside of their skill class, and the drop in male participation rates during the past several decades can be explained in part by a drying-up of middle-skill job opportunities. Taken together, these results imply that any model relating polarization to middle-skill employment fluctuations must go beyond pure search motives to include industry-level effects as well as a labor force participation margin. The results thus provide encouragement for a growing literature that integrates "macro-labor" search models with "macro-macro" models featuring differential industry cyclicalities and convex preferences over consumption and leisure.
\end{abstract}

*Prepared for the 2014 NBER Macroeconomics Annual. The views in this paper are not necessarily those of the Federal Reserve Bank of Boston or the Federal Reserve System. Matthew Curtis and Ryan Ruxlow provided outstanding research assistance. For helpful comments we thank, without implicating, the editors (Jonathan Parker and Michael Woodford), Daron Acemoglu, David Autor, Ryan Michaels, Claire Reicher, Paul Willen, and seminar participants at a number of institutions. Thanks are also due to Autor, David Dorn, and Melanie Wasserman for sharing their occupational classification codes. Remaining errors are our responsibility.

${ }^{\dagger}$ Federal Reserve Bank of Boston. Email: Chris.Foote@bos.frb.org.

$\ddagger$ University of Michigan. Email: RichRyan@umich.edu. 


\section{Introduction}

A recurring question for macroeconomists and policymakers is how low-frequency employments trends affect cyclical employment fluctuations for different groups of workers. In the U.S. labor market, a fundamental long-run trend is polarization, which describes the relative growth of high- and low-skill job opportunities and decline of middle-skill jobs. ${ }^{1}$ As seen in the decadal Census data at the top of Figure 1, some time after 1960 the share of nonagricultural middle-skill jobs begins a protracted decline that mimics the drop in agricultural jobs in the first half of the 20th century. ${ }^{2}$ Polarization stems from two complementary forces: automation, which replaces workers in routine occupations like assembly-line work or clerical jobs with machines or computers, and international trade, which encourages firms to offshore routine tasks to countries where wages are lower. Jobs in the middle part of the skill distribution suffer more from automation and trade because these jobs tend to encompass more routine tasks than high- or low-skill jobs. A potential link between long-run polarization and recent cyclical job losses is evident in Panel B of Figure 1, which plots indexed employment levels by skill during and after the Great Recession. Employment growth for high-, middle-, and low-skill workers slows markedly during the recession, but only the middle-skill group experiences a sharp and lasting employment decline.

A link between polarization and the recent drop in middle-skill employment can be consistent with formal search-and-matching models of the labor market (Mortensen and Pissarides 1994; Pissarides 2000). A search friction is these models prevents unemployed workers from instantly matching with firms posting vacancies. In response to some key inconsistencies with business-cycle facts identified by Shimer (2005), some search models, in order to match the large drop in the job-finding rate of unemployed workers that occurs when aggregate productivity declines, include a second friction: sticky real wages. ${ }^{3}$ Although calibrating a search model with an endogenous job-separation margin and match-specific movements in productivity is technically challenging (Pissarides 2009), forward looking firms and workers are likely to dissolve matches with poor long-run prospects more quickly than other matches when aggregate productivity declines. As a result, standard search models are qualitatively consistent with large middle-skill job losses experienced during the Great Recession.

\footnotetext{
${ }^{1}$ Examples of empirical and theoretical work on polarization include Autor, Levy, and Murnane (2003), Autor, Katz, and Kearney (2008), Goos, Manning, and Salomons (2009), Autor (2010), Acemoglu and Autor (2011), and Autor and Dorn (2013). Recent papers on cyclical aspects of polarization include Faberman and Mazumder (2012), Jaimovich and Siu (2013), Smith (2013), Tüzemen and Willis (2013), and Cortes et al. (2013).

${ }^{2}$ The Census data are from IPUMS (Ruggles et al. 2010) and make use of its 1950 occupational classification code (OCC1950). We provide more details of the classification of nonagricultural employment into high-, middle-, and low-skill jobs in the next section.

${ }^{3}$ As explained by Hall (2005), the incentive of a firm to post a vacancy falls sharply if productivity declines and the wage is held fixed. The resulting drop in posted vacancies explains the observed drop in job-finding rates and the increase in the unemployment rate when recessions occur.
} 
In this paper, however, we argue that the textbook model of search must be expanded in important ways if it is to match the occupational pattern of employment fluctuations. To begin with, search models often have only one production sector and no capital, but the data suggest that volatility of investment is a key reason for the large fluctuations in middle-skill employment. A new dataset shows that over the postwar era, the most cyclical group of middle-skill workers is the group with the strongest representation in manufacturing and construction, two industries that fluctuate along with investment and durable-goods consumption over the business cycle. The cyclical behavior of this particular middle-skill group remained remarkably stable over postwar era, even as the negative trend in overall middle-skill employment became more firmly entrenched. Additionally, individual-level data on movements between employment (E) and unemployment (U) show that EU flows for middle-skill workers in manufacturing and construction "spike" in recessions more so than EU flows for other middle-skill workers. Spikes in middle-manufacturing employment are potentially consistent with middle-skill manufacturing workers optimally reallocating en masse in recessions, because employment for this group of workers has been declining for decades. But middle-construction workers also experience EU spikes, even though - in contrast to the overall middle-skill trend-employment for middle-construction workers rose over time.

A second fact arguing against a pure search-based explanation for recent middle-skill job losses is that middle-skill workers rarely exit unemployment for either high- or low-skill jobs. Given their position in the middle of the skill distribution, the inability of these workers to exit unemployment for a high-skill job is perhaps not surprising and, to be sure, this probability rises if the middle-skill worker has a college degree. But unemployed middle-skill workers also appear averse to exiting unemployment for low-skill jobs at any stage of the business cycle. Moreover, as employment in middle-manufacturing jobs has trended down, a rising proportion of unemployed workers from this category have taken middle-skill jobs outside of manufacturing and construction, suggesting that it is either impossible or unattractive for middle-manufacturing workers to switch skill classes. In all, optimal switching out of middleskill employment does not appear to be a first-order determinant of middle-skill employment fluctuations.

The final empirical finding concerns the nonparticipation margin. To preserve parsimony, this margin is typically omitted from high-frequency search models as well as models from the labor literature that model polarization over the long run (Acemoglu and Autor 2011; Autor and Dorn 2013). In the long-run models, the evolution of opportunities for workers with varying skill levels will affect the occupational distribution of employment, as well as the wages that different workers receive. But workers are assumed to supply labor inelastically with respect to the wage, so labor force participation is always complete. If middle-skill workers lack either the skills or desire to take jobs in other skill classes, as cyclical results 
imply, then a drying-up of middle-skill opportunities would be at least partly reflected in lower participation rates for people specializing in middle-skill work. Some suggestive evidence for a relationship between polarization and nonparticipation appears in Panel C of Figure 1. The participation rate for prime-age males has declined steadily since the early 1960s, about the time that polarization begins.

Studying the participation decisions of middle-skill workers over the short-run is difficult, because the Current Population Survey (CPS) does not include occupational information for people who drop out of the labor force. But a long-run empirical model used by Acemoglu and Autor (2011) to study wages can be easily adapted to study participation. This model is specified at the level of the demographic group, obviating the need to follow individual workers over time. The estimated model shows that demographic categories specializing in middle-skill work in the late 1970s (such as young, noncollege men in particular Census divisions) have much lower participation rates today. In fact, the model implies that the ongoing decline in middle-skill job opportunities goes a long way in explaining the drop in prime-age male participation over this period. While this finding should be complemented by data that follow individuals over time, it provides additional evidence that middle-skill employment alternatives are limited, so reallocation and job search may be less important drivers of middle-skill employment movements.

By presenting some new facts about occupational patterns of employment fluctuations, this paper is potentially useful for a growing literature that integrates search-and-matching models of the labor market with DSGE models in the RBC or New Keynesian tradition. ${ }^{4}$ In particular, this literature blends elements like nominal frictions in product markets and convex preferences over consumption and leisure to search models. The goal of this work is to produce models that can, for example, illustrate how optimal monetary policy is affected by differences in labor-market institutions. Our findings suggest that a blended model with volatile investment and an active participation margin will be needed to explain employment fluctuations at the occupational level. The negative long-run trend in middle-skill employment may be play an important role in this model, but mainly to encourage separations from declining middle-skill occupations into nonparticipation, not into job search. More speculatively, the volatile labor demand in traditional middle-skill employers may change the nature of unemployment, so that it serves as a "holding tank" for workers who plan on returning to their old firms once labor demand improves. ${ }^{5}$ Over the long run, the empirical link between polarization and participation outlined below suggests that polarization may not be reflected

\footnotetext{
${ }^{4}$ Blanchard and Galí (2010) provide an example of such a model as well as an excellent summary of the literature. See also Krause and Lubik (2007) and Gertler and Trigari (2009) for papers that integrate "macro-labor" models with "macro-macro" models.

${ }^{5}$ Below we discuss work by Fujita and Moscarini (2013), who show that unemployed workers often return to their former employers. Such returns might be especially frequent for middle-skill workers in volatile industries.
} 
solely in employment and wages, as many long-run models assume.

\section{Historical Cyclicality of Occupational Employment and Unemployment}

\subsection{Data}

Figure 1 showed the severity of recent middle-skill job losses, but were these losses abnormal given the depth of the Great Recession? Answering this question requires the construction of a new dataset, because official occupational data on employment levels and unemployment rates are available only after January 1983 and January 2000, respectively. Earlier data are not available because the government's occupational designations change about every 10 years and BLS officials are not comfortable extending series corresponding to current occupations further back in time. It is possible to construct longer time series by using contemporary labor-market reports published by the BLS and the Census Bureau. Soon after World War II, regular Census reports on the labor force included occupational employment levels for the first month of each quarter. Monthly data become available in January 1958. Because occupational data are available only for January, April, July, and October before January 1958, the seasonal properties of a quarterly employment dataset will change in that month. We take account of that fact when seasonally adjusting the data, as explained in the online appendix. Our dataset runs from 1947q3 to 2013q4.

As pointed out by Jaimovich and Siu (2013), the early occupational data can be aggregated into four broad groups based on routine vs. nonroutine and cognitive vs. manual distinctions. ${ }^{6}$ Table 1 shows that the nonroutine cognitive group consists of high-skill workers doing managerial, technical, or professional tasks. And at the other end of the skill spectrum are low-skill service occupations, such as cooks and waiters, security guards, groundskeepers, and janitors. The nonroutine nature of both groups makes these tasks difficult to automate or offshore. More susceptible to displacement are the two routine categories in the middle of the skill distribution. Routine cognitive workers generally perform sales and clerical tasks. Like high-skill workers, routine cognitive workers use brains rather than brawn, but the routine nature of sales and clerical jobs makes these workers more vulnerable to displacement. The other middle-skill group consist of routine manual workers who operate machines on factory assembly lines, work on construction sites, or perform other types of production work.

The columns of Table 1 list the official major occupational groups in selected decades. Individually, major occupational groups undergo significant changes. A factory worker might be classified as an "operative or kindred worker" using the 1940 designations but a "production" worker using the 2010 designations. But the table shows that the shifting subgroups

\footnotetext{
${ }^{6}$ The theoretical section of Jaimovich and Siu (2013) includes a search-and-matching model that links polarization to the recent phenomena of jobless recoveries. We discuss that model below.
} 
still can be aggregated consistently into the four broad groups over the entire postwar era. This is not to say that "seams" in the data never arise when official classifications change. The two most important seams occur in 1971 and 1983 with the introduction of the 1970 and 1980 classification systems, respectively. The online appendix describes our method for dealing with these seams and our checks to ensure that the resulting data series are consistent.

Though the published data do not allow us to disaggregate occupational employment along other dimensions, such as industry, decadal Census data can shed light on the composition of the four occupational groups over time. The IPUMS data (Ruggles et al. 2010) includes an occupational variable, OCC1950, that aggregates occupational categories used in various census years into a single classification system based on the 1950 major occupational groups. We are therefore able to aggregate individual records from decadal IPUMS data into the four broad groups in Table $1 .^{7}$ We are also able to use a consistent industry code in IPUMS (IND1950) to determine the industry composition of the four groups in census years, and the manufacturing and construction shares of employment for the groups are graphed in Figure 2. The two panels show that routine manual workers are disproportionately employed in manufacturing and construction. After 1960, the share of manufacturing employment in the routine manual group declines, as it does for all groups. But after 1980 the manufacturing decline in the routine manual group is partially offset by an increase in the share of employment in construction, another cyclical industry.

Figure 3 plots log employment levels for the four broad groups beginning in 1947q3, along with Hodrick-Prescott (HP) trends $(\lambda=100,000)$. The series include the two seam adjustments in 1987 and 1983, but are not seasonally adjusted, and the panels have different vertical scales. As we might expect from its significant representation in manufacturing and construction, routine manual employment has traditionally been far more cyclical over both the seasonal and business cycles than employment in the other three groups. ${ }^{8}$ Another takeaway of Figure 3 is that we must be careful when using HP filters to detrend these data. HP trends are well known to have "endpoint problems;" that is, to be unduly influenced by movements at the end of the sample period. The big declines in employment for routine cognitive workers (Panel B) and routine manual workers (Panel C) during the Great Recession appear to have pulled down the HP trend in recent years, even with a relatively high smoothing parameter (100,000). Figure 4 graphs the shares of employment for the four groups, which are consistent with the implied shares from Census data displayed in Figure 1. As noted by Goldin and Katz (2008), a progressively higher share of employment is accounted for by

\footnotetext{
${ }^{7}$ The 1950 major occupational groups are essentially the same as the 1940 groups in the first column of Table 1. We also use OCC1950 to construct the top panel of Figure 1.

${ }^{8}$ Note that seasonal properties of the nonroutine manual workers in Panel D appear to change in 1983, when the 1980 occupation codes are introduced. Whenever we seasonally adjust the data, we therefore allow a different seasonal cycle to begin at that point.
} 
high-skill occupations as the technological demands of the economy grew. The share of routine manual employment has declined steadily over the same period, even though Panel $\mathrm{C}$ of Figure 3 showed that routine manual employment has generally trended higher in absolute terms. The share of employment for the other middle-skill group, routine cognitive workers, rose along with the high-skill share in the early postwar era but leveled off after 1970 and has begun to decline more recently.

Starting in 1957, we are able to obtain unemployment levels disaggregated by the last job that the unemployed person held, which remains the standard convention for BLS measurement of unemployment by occupation. Consistent published data are available on a quarterly, seasonally adjusted basis through the end of 1981, and the online appendix explains how we code the OCC1950 variable into our CPS microdata to calculate unemployment rates for the four groups after that point. The resulting unemployment rates appear in Figure 5. The top panel shows that while occupational unemployment rates have different average levels, they move together strongly over time. This pattern is also true of post-2000 occupational unemployment rates that the BLS publishes today, as well as of unemployment rates disaggregated along other dimensions (for example, by education). The lower panel of Figure 5 graphs the ratios of the four individual rates relative to the aggregate unemployment rate. As implied by the previous panel, unemployment for routine manual workers is typically higher than other groups and becomes more so in recessions, though its usual cyclical increase was muted in the mild recessions of 1990-91 and 2001.

Relative unemployment for the other middle-skill group, routine cognitive workers, rises smoothly from about 1980 until the early 2000s, which lines up well with the low-frequency decline in the share of employment for this particular middle-skill group depicted in Figure 4. However, relative routine cognitive unemployment does not display the same cyclical pattern as it does for the routine manual group. Relative unemployment for the groups at the ends of the skill distribution also display interesting patterns. Unemployment rates for high-skill, nonroutine cognitive workers is typically much lower than for other workers, but relative unemployment for this group has trended higher for most of the sample period and underwent a noticeable increase during the 2001 recession. Unemployment rates for the low-skill, nonroutine manual group are generally high, but they tend to fall in relative terms during recessions, indicating that recessionary increases in unemployment for low-skill workers are relatively mild.

\subsection{Cyclical patterns in employment and unemployment}

We now provide some basic evidence on the high-frequency relationship between employment and unemployment at the occupational level with real GDP. To do so, we detrend all series 
with HP filters that share the same smoothing parameter $(\lambda=100,000) .{ }^{9}$ We then construct rolling 10-year correlations of detrended GDP with detrended employment and detrended unemployment. Results appear in Figure 6. Considering first the GDP-unemployment correlations, the common pattern among unemployment rates we saw in the top panel of Figure 5 suggests that all four unemployment rates should be negatively correlated with GDP, and the rolling correlations bear this out. For each group, the GDP-unemployment correlation is strongly negative and near -1 throughout the sample period. On the other hand, the GDPemployment correlations vary widely. For middle-skill routine manual workers in Panel C, this correlation is uniformly large and positive, consistent with the strong cyclical pattern for routine manual employment shown in Figure 3. By contrast, the GDP-employment correlation for the low-skill nonroutine manual workers in Panel D hovers near zero, indicating acyclical employment levels. Somewhere between these two extremes lies the cognitive workers in Panels A and B, where GDP-employment correlations rise over time. The increase occurs somewhat earlier for the middle-skill routine-cognitive-employment workers in Panel $\mathrm{B}$ than for the high-skill nonroutine cognitive group in Panel A. ${ }^{10}$

The moving correlations paint a broad picture of labor market cyclicality, but the discussion of particular recessions requires a regression model. Our first regression is a type of dynamic factor model (DFM), which are often used to measure the impact of a single cyclical factor on individual time series. Our DFM is based on detrended log levels data and has the following form:

$$
\begin{aligned}
F_{t} & =\rho F_{t-1}+\theta G D P_{t}+\nu_{t} \\
E_{i t} & =\alpha_{i}+\phi_{i} F_{t}+\beta_{1 i} M f g_{t}+\beta_{2 i} \text { ResConstr }_{t}+e_{i t} .
\end{aligned}
$$

Here $F_{t}$ is a single, unobserved common factor that depends on GDP and is constrained to be an $\operatorname{AR}(1)$ process with error term $\nu_{t} .{ }^{11}$ The four employment series $E_{i t}$ depend on the common business-cycle factor $F_{t}$, group-specific constants $\alpha_{i}$, manufacturing output $M f g_{t}$,

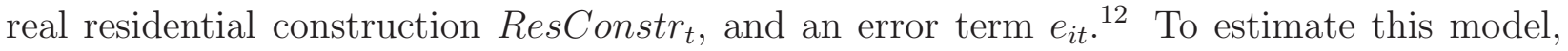
we assume that the disturbance terms $\nu_{t}$ and $e_{i t}$ are normally distributed, which allows joint

\footnotetext{
${ }^{9}$ Recall that this parameter is also used for the employment trends graphed in Figure 3.

${ }^{10}$ In an accounting sense, disparate correlations of GDP with employment levels may appear hard to reconcile with the negative and stable unemployment GDP-correlations. In a world with no population growth, one type of occupation, and no labor force participation margin, the size of the labor force cannot change, so increases in unemployment must result in employment declines. Yet more complicated models could admit changes in unemployment that coincide with intensified movements of workers across occupations, or changes in movements in and out of the labor force. These extensions would allow the correlations of GDP with occupation-specific employment and unemployment to differ.

${ }^{11}$ The variance of $\nu_{t}$ is normalized to equal one.

${ }^{12}$ Manufacturing output comes from the Federal Reserve Board's industrial production release and residential construction comes from the national accounts. Both series are residuals from HP trends with $\lambda=100,000$, as are the other variables in the model.
} 
estimation of the system as a state-space model via maximum likelihood and the Kalman filter. ${ }^{13}$ To assess potential changes in the cyclicality of detrended employment over time, the DFM is estimated over three sample periods: an early sample that runs from 1947q3 to 1985q4, a later sample that extends from 1986q1 to 2013q4, and a third full sample that uses all the data.

Figure 7 shows how employment in different occupational groups would be expected to change during and after the past three recessions. Each panel begins one year before the start of the recession, denoted with a vertical line, and ends four years after the recession begins. The lines in the panels correspond to either actual data (black dashed line) or to dynamic predictions from one of the three models distinguished by their estimation periods. The dynamic predictions begin with the onset of each recession and are carried through the subsequent four years. ${ }^{14}$ Turning first to routine-manual-employment panels in the third column, we see that the DFM generates very similar predictions no matter what sample period generates their coefficients. By and large, the predictions for the routine manual group not only track one another closely, they track actual data well, too. Thus, the stability of the GDP-employment relationship apparent in the rolling correlations for routine manual workers carries over to more specific predictions for routine manual employment around recessions.

Other panels of the table also corroborate the correlational patterns. For high-skill workers in the first column, during the 1990-91 recession there is a significant miss for the predictions generated by the earlier data or the full sample, highlighting lack of much high-skill cyclicality in the early sample period. Estimating the DFM on the later model improves matters somewhat, but the gap between predicted and actual data remains large. The same pattern appears to a lesser extent during the 1990-91 recession for the routine cognitive workers in the second column. The earlier models predict more of an employment response for this group, consistent with the earlier rise in cyclicality for routine cognitive workers. Finally, the fourth column shows that there is never much movement in the employment for the low-skill workers in the nonroutine manual group, either in the predictions of the DFM or in actual data.

As noted above, estimating a model with HP-detrended levels data has a potential drawback near the endpoints of the sample. Figure 3 shows that even with a strict smoothing

\footnotetext{
${ }^{13}$ The individual errors $\epsilon_{i t}$ are allowed to follow $\operatorname{AR}(1)$ processes. Maximum likelihood (ML) estimation is feasible here because the number of employment series in the system is small. ML estimation is infeasible in large systems now common in empirical macroeconomics. The abundance of information in these systems means that it is usually appropriate to estimate the factors by principal components analysis, then treat them as data for further analysis (Stock and Watson 2011). For an application of this approach, see Stock and Watson (2012).

${ }^{14}$ The predictions are dynamic because they use no actual employment data once they begin, only actual real-side data such as GDP.
} 
parameter of $\lambda=100,000$, the HP filter suffers the common problem of being unduly influenced by endpoints. In light of this drawback, we estimate a model of occupational employment in log differences rather than detrended log levels to evaluate behavior during and after the Great Recession. As before, we specify early, late, and full-sample periods over which to estimate the differenced models. Unlike the levels-based DFMs, however, we simply fold the GDP data into the observed equations, so that the model consists of four independent regressions rather than four observed equations linked by a common factor. ${ }^{15}$ We also end the full and later sample periods in $2007 q 3$ rather than 2013q4, so that the dynamic forecasts constructed at the onset of the Great Recession are true out-of-sample forecasts as well as dynamic forecasts. Finally, in order to generate comparisons with log levels data, the predicted log levels of employment are constructed by summing the dynamically forecasted log differences. ${ }^{16}$

The results of the differenced model are presented in Figure 8. This figure is generally consistent with the main lessons of the previous DFM, but it shows that the HP-endpoint problem could be an issue for middle-skill routine cognitive workers depicted in Panel B. The levels-based DFM did a passable job of explaining routine cognitive employment after the Great Recession, but recall that the recession pulled the HP trend much lower for routine cognitive workers. ${ }^{17}$ In the differenced model, which does not include a time-varying trend, Panel B shows that even a regression estimated on the most recent sample misses the large employment drop for routine cognitive workers during the Great Recession. Misses for the other groups are less substantial.

\subsection{Summing up the historical results}

Perhaps the most interesting takeaway from this section concerns of the two manual groups, which are at opposite ends of the spectrum as far as employment cyclicality is concerned. Employment for the middle-skill routine manual group has always varied strongly over the business cycle, while that of the low-skill nonroutine manual group never has. Indeed, though unemployment rates for the low-skill group are high on average, the relative unemployment rate for low-skill workers improves in recessions. These patterns are consistent with expected fluctuations in labor demand for the two manual groups. Routine manual workers tend

\footnotetext{
${ }^{15}$ The differenced model is therefore four independent regressions without a state equation.

${ }^{16}$ Each regression projets the log difference of an employment series on the contemporaneous difference and two lags of log GDP, log manufacturing output, and log residential construction. Lags of the dependent variable are not included. We were concerned about seasonally adjusting the data before entering it into the differenced model, so we left the model in not-seasonally-adjusted form. To account for seasonality, we included seasonal dummies in the regressions with interactions allowing for changes in the seasonal cycle in 1958 (when the quarterly data can be constructed by averaging monthly data) and in 1983 (because the use of the 1980 occupation codes appears to affect seasonality in the low-skill, nonroutine manual group).

${ }^{17}$ See the bottom panel in the second column of Figure 7 for the routine-manual results from the levels-based DFM.
} 
to work in factories and construction sites, where labor demand changes greatly over the cycle. Nonroutine manual occupations include many "maintenance" or "overhead" occupations such as janitors and security guards, as well as occupations associated with nondurable consumption, such as cooks and waiters. In these areas labor demand is more stable.

Employment cyclicality for the two cognitive groups is harder to summarize because it rises over time. For both high-skill nonroutine cognitive workers and the middle-skill routine cognitive workers, rising cyclicality shows up in both simple rolling correlations of employment with GDP and in underpredictions of employment levels around recent recessions when models are estimated over early sample periods. For the sales and clerical workers in the routine cognitive group, rising cyclicality could be theoretically related to a downward trend in the employment share during the past several decades. However, the timing is not right. Figure 6 shows that the rolling correlation of employment and GDP for routine cognitive workers reaches something close to its current positive value by the early 1970s, before the routine cognitive share begins to fall. The timing is better for a relationship between the declining routine cognitive employment share and the low-frequency rise in relative unemployment for routine-cognitive workers depicted in the lower panel of Figure 5. In any case, rising cyclicality for high-skill workers complicates any explanation for the routine cognitive group that relies on polarization forces alone.

Finally, the historical results above bear on whether recent recoveries should be considered "jobless." Papers including Galí, Smets, and Wouters (2012) have noted that lackluster employment growth in recent recoveries is not surprising in light of the weak recoveries in GDP. These papers contend that a better label for recent recoveries is "slow," not jobless. With the possible exception of the routine cognitive workers in the Great Recession, the two sets of regression results indicate that this reasoning remains valid when we consider employment movements for individual occupational groups as well for the entire economy.

\section{Middle-skill Flows into Unemployment: The Importance of Industry}

CPS microdata become available only in January 1976, but these data are critical to any cyclical study of polarization because they allow disaggregation by industry as well as the measurement of flows in and out of unemployment. ${ }^{18}$ The importance of industry on occupational employment is evident in Figure 9, which depicts quarterly averages of monthly employment levels for two occupational categories: all high- and low-skill workers (solid line) and all routine middle-skill workers (dashed line). Panel A shows that polarization has occurred within manufacturing since at least the early 1980s, though high-skill manufacturing

\footnotetext{
${ }^{18}$ CPS microdata contain more detailed occupational classifications than those used in the historical analysis. We make use of this detail, which is also used in Autor (2010) and Acemoglu and Autor (2011). See the online appendix for details.
} 
employment began to decline shortly before the 2001 recession. ${ }^{19}$ By contrast, polarization is not a feature of construction employment. Panel B shows that middle-skill construction employment grows in lockstep with employment at the ends of the skill distribution until the Great Recession. In the historical analysis, construction workers were placed in the middle-skill category by necessity; Table 1 shows that the government did not include a major occupational group for "Construction and Extraction Occupations" until recently. But workers on construction sites are harder to replace with robots than workers on assembly lines, and the buildings, roads and bridges that construction workers produce cannot be fabricated abroad and shipped to the United States. It is therefore reasonable to find a lack of polarization within the construction sector. The final panel of Figure 9 displays employment data for industries other than manufacturing and construction. A slowdown in middle-skill employment growth is apparent from the mid-1980s onward and middle-skill employment losses are large in the Great Recession. Both time-series patterns are consistent with earlier results regarding routine cognitive workers, who make up about 70 percent of middle-skill workers outside of the two goods-producing industries. ${ }^{20}$

How do these trends correlate with flows into unemployment during recessions? Figure 10 graphs transition rates from employment to unemployment (EU) for middle-skill workers disaggregated by industry. These rates are adjusted for both the changing demographic composition within each group over the sample period and for time aggregation. ${ }^{21}$ The figure reveals sharp cyclical differences in EU flows by industry, in that job separations among middle-construction and middle-manufacturing workers spike in recessions to a greater degree than for middle-skill workers in other industries. Could these spikes reflect a higher willingness of middle-skill workers in construction and manufacturing to separate into unemployment due to unfavorable long-run trends? Such a story might be reasonable for middlemanufacturing workers, where employment has long been declining. But Figure 9 also showed that middle-skill employment in construction has been rising over time, making it hard to interpret the middle-construction spikes as short-run reactions to long-run trends. These spikes instead support a story based on volatile labor demand in the two goods-producing industries. Additionally, EU flows for middle-other employment appear to have a common recessionary pattern over the sample period, even though Figure 9 showed a change in trend employment growth from the beginning of the sample to the end.

\footnotetext{
${ }^{19}$ The solid line in the manufacturing panel consists almost entirely of high-skill workers, since low-skill service workers rarely work in the manufacturing sector. The same is true of the construction data in Panel B.

${ }^{20} \mathrm{By}$ contrast, about 80 percent of middle-skill manufacturing workers and 90 percent of middle-skill construction workers are in the routine manual group.

${ }^{21}$ See the online appendix for details of these adjustments. A time-aggregation correction is needed because the point-in-time nature of the CPS complicates the estimation of continuous transition rates though employment, unemployment, and nonparticipation. See the data appendix for details of both the demographic adjustment and the time-aggregation correction.
} 
Before closing this section, we note another potential advantage of disaggregating EU flows by industry. A long literature has studied the degree to which unemployment rises in recessions because of higher inflows into the unemployment pool versus lower outflows out of it (Shimer 2005; Elsby, Michaels, and Solon 2009; Shimer 2012). The results above show that EU flows have a strong industry component, so taking industry into account may help models match these flows. In other words, matching the true time-series pattern of EU flows in a standard search model with 1 percent fluctuations in aggregate productivity may be difficult. Matching those flows with a model in which manufacturing and/or construction output gyrate in recessions on the order of 10-30 percent, perhaps due to nominal frictions or rapid changes in demand for durable goods, may be easier.

\section{Employment Alternatives for Unemployed Middle-Skill Workers}

We next follow middle-skill workers into the unemployment pool to get a sense of their employment alternatives once they are there. To provide some context for this analysis, the top panel of Figure 11 plots the destinations of middle-skill workers who move to new employers without experiencing a (measured) spell of unemployment. These so-called EE flows are available beginning in 1994 after the major redesign of the CPS and are smoothed in the figure with a four-quarter trailing moving average. For all three types of middle-skill workers, the most common destination after an EE flow is to the same type of job that the worker held before. Even movements to other middle-skill categories are rare, though middlemanufacturing workers transition to middle-other jobs about 25 percent of the time while middle-construction workers do so somewhat less frequently. For all types of middle-skill workers, transitions to high-skill jobs are uncommon, though middle-other workers are able to accomplish this feat more frequently than the other two groups.

The lower panel of Figure 11 plots employment destinations for middle-skill UE flows, which can be generated from 1976 onward. Again these are smoothed with a four-quarter moving average. As with the EE flows, middle-skill UE flows that result in a new job usually end with the worker in the same middle-skill category that he left. But there are some interesting differences relative to the EE flows. First, for unemployed middle-manufacturing workers, the probability transitioning back to middle-manufacturing declines throughout the sample, consistent with the declining trend in middle-manufacturing employment from Figure 9. Because the UE probabilities must sum to one, this negative trend must be offset in some way. And a rising probability of UE flows from middle-manufacturing to the middle-other group is largely responsible for doing so. A second lesson from the UE flows is that these flows to high-skill jobs are less frequent then EE movements to high-skill work. In particular, the share of middle-other flows to high-skill work via an EE flow averages 13.8 percent during the period of data availability (1994q1-2013q4). The share of middle-other UE flows ending 
in a high-skill job over the same period is 9.7 percent. $^{22}$

\subsection{A discrete-choice model of unemployment transitions}

The probabilities plotted in Figure 11 show that a large majority of middle-skill reallocation is to other middle-skill jobs, and that the likelihood of getting a high-skill job is not necessarily enhanced by moving through the unemployment pool. As descriptions of the outside alternatives available to middle-skill workers, however, the raw means in Figure 11 are incomplete. The probabilities take no account of worker characteristics such as age or education. These characteristics vary at low frequencies (because of the aging of the labor force) and perhaps over the business cycle as well. Additionally, the UE probabilities are calculated conditional on exiting unemployment for another job, yet many unemployment spells end in transitions to nonparticipation rather than employment. And to learn about the reallocation decisions of middle-skill workers in recessions, it would be useful to measure middle-skill reallocation with reference to a specific cyclical indicator.

A multinomial logit model for middle-skill transitions out of unemployment accounts for these issues. Consider an unemployed middle-skill worker $j$ from industry $i$ who can either stay unemployed (U), exit to employment (E), or exit to nonparticipation $(\mathrm{N})$. With remaining in $\mathrm{U}$ normalized as the baseline choice, the unconditional probabilities of transitioning from unemployment to either $\mathrm{E}$ or $\mathrm{N}$ are:

$$
\begin{aligned}
& \operatorname{Pr}\left(E_{i j, t+1} \mid U_{i j t}\right)=\frac{\exp \left(\Gamma_{i E}^{\prime} X_{i j t}\right)}{1+\exp \left(\Gamma_{i E}^{\prime} X_{i j t}\right)+\exp \left(\Gamma_{i N}^{\prime} X_{i j t}\right)} \quad \text { and } \\
& \operatorname{Pr}\left(N_{i j, t+1} \mid U_{i j t}\right)=\frac{\exp \left(\Gamma_{i N}^{\prime} X_{i j t}\right)}{1+\exp \left(\Gamma_{i E}^{\prime} X_{i j t}\right)+\exp \left(\Gamma_{i N}^{\prime} X_{i j t}\right)},
\end{aligned}
$$

where $X_{i j t}$ is a vector of regressors and the $\Gamma$ s are parameters. For notational convenience, this representation does not distinguish between exits to high-skill, middle-skill, or low-skill employment, though we allow different types of employment exits in the actual model. Demographic characteristics of workers are included in the $X$ vector, as the CPS data can generate controls for educational attainment, gender, marital status, and age. Because the CPS also measures unemployment duration, this variable can also be entered in the model. ${ }^{23}$ To cap-

\footnotetext{
${ }^{22}$ For middle-manufacturing and middle-other workers, the probabilities of transitioning to a high-skill job in the 1994q1-2013q4 period are 9.4 percent via an EE flow and 5.3 percent via a UE flow. The corresponding probabilities for middle-construction workers are 6.9 and 4.1 percent, respectively.

${ }^{23}$ Age is specified as a cubic polynomial in the worker's true age minus 35 years, so that all three age terms equal zero when the worker is 35 years old. Dummies are entered for nonwhite, female, and married. The three included education categories are less-than-high-school, some college, and college graduate, as highschool graduate is the omitted educational category. The female dummy is interacted with the nonwhite and married dummy as well as the cubic in age -35 . The duration dummies correspond to 2, 3, 4, 5-8, 9-13, 14-17, 18-21, 22-26, 27-51,52, 53-78, 79-98, 99, and > 99 weeks of duration (zero duration is omitted). We also exclude workers who are more than 70 years old from the estimation sample and include quarterly
} 
ture the effect of the business cycle on middle-skill employment transitions, we specify an "average" job-finding rate for all workers in the economy. This rate generated from a system of unemployment-to-employment probabilities (UE rates) corresponding to five industryskill groups: the three middle-skill groups disaggregated by industry plus high- and low-skill workers. The cyclical indicator is the common factor generated by a dynamic factor model on this system with no covariates, other than quarterly dummies in the individual observation equations. ${ }^{24}$ With this cyclical indicator, the model measures how the destinations of unemployed middle-skill workers change as jobs become easier or more difficult to find.

Figure 12 displays the resulting transition probabilities for a baseline worker who is 35 years old, male, unmarried, and white. The probabilities on the left side of each panel are applicable when the baseline worker has high-school diploma but no further education, while those on the right are for an otherwise identical worker with a college degree. Each panel corresponds to a separate logit estimated for a specific type of middle-skill workers (manufacturing, construction, or other). The duration dummies are zeroed out when calculating the probabilities, so the bars depict transition probabilities for unemployed workers with zero to one weeks of duration. Darker bars are the relevant probabilities when the common finding factor is one standard deviation above its mean, while the lighter bars depict probabilities when the finding factor is a standard deviation below. Two key take-aways emerge. First, the panels reinforce the message of Figure 11: unemployed middle-skill workers tend to stay in middle-skill jobs. Baseline workers with college degrees transition to high-skill jobs more often than less-educated workers, but the effect of higher education is modest. A second lesson is that the business cycle does not have much effect on probabilities other than those for moving to a middle-skill job or staying unemployed. An increase in the economywide job finding rate makes it more likely that a baseline middle-skill worker is able to return to middle-skill work. But because no other transitions are significantly affected, the only other effect of a tighter labor market is to reduce the probability that the worker remains in the unemployment pool.

The transition probabilities in Figure 12 assume that duration equals one week or less. In some unreported work, we calculated implied transition probabilities for workers with varying levels of duration, assuming that the overall finding-rate factor is fixed at its mean. We found that transitions to high- or low-skill jobs did not become noticeably higher the longer that the worker remained unemployed. Indeed, the only duration dependence that we found in this analysis was a negative duration dependence for a return of the unemployed worker back to

dummies (the first quarter is omitted).

${ }^{24}$ This common factor is constrained to follow an $\mathrm{AR}(1)$ process, but it is essentially identical to what emerges from a simple principal components analysis of the UE rates for the five industry-skill groups. Like the finding rates disaggregated by education in Elsby, Hobijn, and Şahin (2010), these UE rates move closely together, as a single principal factor explains more than 90 percent of their time-series variation. 
the same skill class. This finding is consistent with recent work on unemployment and recalls by Fujita and Moscarini (2013), who use data from the Survey of Income and Program Participation (SIPP). The SIPP can reveal whether an unemployed worker is eventually recalled to the same employer, and the authors find not only that recalls are common, but also that negative duration dependence in re-employment exists only for recalls to the same firm. In any effect, the logits do not support the idea that middle-skill workers find searching for other types of jobs more or less attractive in recessions. ${ }^{25}$

\section{Polarization and Labor Force Participation}

Results in the previous section suggest that employment alternatives for middle-skill workers are limited, with the implication that these workers are not entering unemployment during recessions to look for new jobs. Negative long-run trends could encourage middle-skill workers in relatively unproductive matches to leave the labor force, however. A potential relationship between polarization and labor-force participation is not just of academic interest. After the Great Recession, much of the decline in the unemployment rate resulted in an accounting sense from continuing declines in the aggregate participation rate because workers without jobs are not counted as unemployed if they are no longer looking for work. ${ }^{26}$ To be sure, much of the post-recession participation decline is an expected consequence of population aging, as the leading edge of the baby boom has now reached traditional retirement ages. But as we saw for prime-age males in Figure 1, participation for younger groups has declined as well.

In this section, we study polarization and participation by adapting an empirical model appropriate for a labor market with a formal occupational structure. This model is grounded in a theoretical framework that Acemoglu and Autor (2011, henceforth AA) offer as a richer alternative to a model traditionally used in labor studies. In what AA call the canonical labor market model, workers with different skills (for example, high and low) are combined

\footnotetext{
${ }^{25}$ The empirical work here can be viewed in the context of a broader literature on occupational mobility over the business cycle. Moscarini and Vella (2008) use three-digit occupations in the CPS to show that occupational mobility is "noisier," or less consistent with regular demographic patterns, in recessions. Hagedorn and Manovskii (2013) show that the finding of Beaudry and DiNardo (1991) that jobs formed in recessions pay relatively low wages for a long time is due to their poor match qualities rather than to implicit contracts. To the extent that these papers show that recessions are poor times to reallocate to new positions, they support our contention that middle-skill workers are probably not separating from their jobs in recessions purely for search motives. But if reallocation patterns during recessions are poor guides to the true alternatives of different workers, they undermine our use of unemployment exits as measures of outside opportunities for middle-skill workers. See also Manovskii and Kambourov (2008) for evidence on long-run patterns in occupational and industry mobility in the 1980s and early 1990s.

${ }^{26}$ The participation rate was 65.7 percent when the Great Recession ended in June 2009. By April 2014, participation had fallen almost three percentage points, to 62.8 percent. The postwar high for participation is 67.3 percent, reached in each of the first four months of 2000 .
} 
with capital in a production function to produce output. In AA's alternative "task-based" model, workers with either high, medium, or low skill levels produce output by performing tasks, or equivalently by working in specific occupations. Worker skill level are exogenous and fixed, but a worker's skills could potentially be assigned to one of many occupations, which vary by complexity. Comparative advantage arguments imply that workers with the highest innate skill levels perform the most complex tasks, workers with mid-level skills work in mid-level occupations, and workers with the lowest innate skill levels perform the least complex tasks. AA contend that their task- or occupation-based model is better suited than the canonical model to capture a variety of labor-market phenomena, of which occupational polarization is one example.

Because workers with different skill levels can move to different occupations along the task-complexity distribution, occupational-level effects of exogenous forces such a polarization or skill-biased technical change are difficult to examine empirically. To see why, consider a single occupation - office administrator - and assume that this job is traditionally performed by workers with mid-level skills. Now assume that high-skill workers become more productive at any given task because of skill-biased technical change. This change may arise because computers become more powerful and because high-skill workers are better able to use computers than people with lower skill levels. When this technical change occurs, high-skill workers using advanced technologies may displace mid-level workers who currently hold office administration jobs. The displacement occurs because high-skill workers are now much more productive as office administrators than middle-skill workers were; in fact, the high productivity of high-skill workers causes the average wage of office administrators to rise over time. Of course, this wage increase does not mean that workers previously working as office administrators are better off. In fact, these workers are worse off because they have been displaced into lower-paying jobs. A series of cross-sectional wage regressions has no way of determining this, however, because workers' skill levels are unobservable. Workers can only be categorized on the basis of basic demographic information and the occupations that they currently hold or most recently held.

The ability to follow individual workers over time can solve some of these problems. In theory, we could then determine what happens to workers who move across occupations in response to various labor-market phenomena. This longitudinal approach motivates our earlier empirical work on unemployment exits. By measuring the destinations of unemployed workers who formerly held middle-skill jobs, we can get a sense of the employment alternatives available to workers who have intermediate levels of innate skill. Even here, we must be careful, however, because some workers with very high or very low innate skill levels will hold middle-skill jobs at some point in their careers. Disproportionate movements of these workers to occupations at the ends of the task-complexity spectrum will then bias our estimates of the 
employment alternatives available to unemployed workers with mid-level skills. Even with these high- and low-skill individuals included as middle-skill workers in our data, however, we find that unemployed workers who formerly held middle-skill jobs rarely move out of the middle-skill category, suggesting that that this source of potential bias is small.

\subsection{A potential regression specification}

Studying nonparticipation by following individual workers is more difficult than studying unemployment exits, however. In the CPS, occupational information is not available for workers who are out of the labor force. For workers who were employed or unemployed in the past, we can conceivably obtain this information by matching across months in the CPS. As pointed out most recently by Elsby, Hobijn, and Şahin (2013), however, many workers cycle though unemployment and nonparticipation, which would require a great deal of matching for workers who enter nonparticipation after a spell of unemployment. But the more matching that is required, the more the resulting dataset deteriorates, due to the inability to match some workers across months, and because of calendar dates when changes in the CPS make all matching impossible.

Consequently, for our study of nonparticipation and polarization we borrow from AA's handbook chapter and estimate the innate skill levels of workers in a different way. AA assume that a worker's innate skill level can be proxied by the occupational distribution of that worker's demographic group in some base year. For example, if most males in Michigan aged 25-30 with high-school diplomas work in middle-skill jobs in the base year, the AA method assumes that the comparative advantage for this group throughout the sample period is in middle-skill tasks. If we later found that men aged 25 to 30 with the same education level and living in the same part of the country were paid low wages, or had higher rates of nonparticipation, we would attribute these changes to polarization. This method does not require us to follow individual workers from demographic groups into lower paying jobs or out of the labor force.

In their paper AA study wage changes for demographic groups using decadal Census data and 1959 as a base year. This model can easily be adapted to study nonparticipation. For our study we use quarterly data for males in the CPS. Let $P_{i}^{H}$ be the baseline share of high-skill employment for demographic group $i$, where the baseline period is defined to extend from the first quarter of 1976, when microlevel CPS data become available, through the fourth quarter of 1981. The shares for middle- and low-skill employment, $P_{i}^{M}$ and $P_{i}^{L}$, are defined analogously. By construction $P_{i}^{H}+P_{i}^{M}+P_{i}^{L}=1$. Following AA, we demarcate our demographic groups on the basis of gender, education, age, and geographic area. We differ from them in that we include only men, we use five-year age groups rather than 10- 
year groups, and we use Census division rather than region as the geographic classification. ${ }^{27}$ Finally, we estimate separate equations for prime-age men (ages 25-54) and older men (55+).

A possible regression specification is:

$$
\begin{aligned}
N_{i t}= & \beta_{t}^{H} \cdot\left(P_{i}^{H} \times \phi_{t}\right)+\beta_{t}^{M} \cdot\left(P_{i}^{M} \times \phi_{t}\right)+\beta_{t}^{L} \cdot\left(P_{i}^{L} \times \phi_{t}\right)+ \\
& \gamma^{e} \cdot \phi_{e}+\gamma^{a} \cdot \phi^{a}+\gamma^{g} \cdot \phi_{g}+e_{i t},
\end{aligned}
$$

where $N_{i t}$ is the nonparticipation share for demographic group $i$ in time quarter $t ; \phi_{e}, \phi_{a}$, and $\phi_{g}$ are dummies for education, age, and geographic groups; and $\phi_{t}$ are time dummies. The $\beta \mathrm{s}$ are the coefficients on the interactions of the time dummies $\phi_{t}$ with the baseline occupational probabilities (the $P$ s), so they will trace out the combined effects of anything that changes the opportunities available to workers with different baseline comparative advantages.

\subsection{Preliminary analysis and long-difference regressions}

Estimating the sample over 1982q1-2013q4, we expect the sequence of $\beta_{t}^{M} \mathrm{~s}$ to be increasing. That is, the demographic groups with baseline comparative advantage in mid-level tasks are likely to experience falling participation rates over time, because middle-skill workers have limited employment alternatives as the demand for mid-level tasks declines over time. To get a better sense of how movements in participation rates for various demographic groups could identify such a pattern, the top panel of Figure 13 graphs baseline 1976-81 occupational shares by age and education for a selected Census division (New England). ${ }^{28}$ The upper left graph in this panel shows that college graduates tended to work in high-skill jobs in the baseline period, as we expect. The next panel to the right shows that workers with some college were about equally likely to work in high- and middle-skill jobs once they reached their mid-30s. The lower two graphs show that the middle-skill shares continue to rise as education declines, at least for men in their prime working years. We might have expected workers without high-school diplomas to be very likely to work in low-skill jobs. The preponderance of these workers in middle-skill jobs indicates that the traditional designation of high-, middle-, and low-skill for occupations does not line up monotonically with observed education levels, at least for men in the baseline period.

The lower panel of the figure graphs the time-series of labor force participation rates for prime-age males, disaggregated by education. Workers with the lowest education levels work the least. More relevant for our purposes, however, is that changes in participation are also related to education. When the CPS microdata sample begins in 1976, participation rates for

\footnotetext{
${ }^{27}$ Both our estimation samples and theirs excludes workers younger than 25 years old. Their wage equation excludes workers older than 64 years old; our participation equation includes these older workers.

${ }^{28}$ Other Census divisions display patterns that are similar, but of course not quite identical. There is therefore some cross-division variation available to help identify the model.
} 
the three most-educated groups are bunched together above 95 percent. Over time, the rate for high-school workers falls by more than 10 percentage points, the some-college rate falls by a little more than 5 percentage points, and the rate for college graduates barely declines at all. ${ }^{29}$

Because education is negatively related to baseline middle-skill shares, the panel regression will attribute some of the average participation decline over the sample period to initial occupational shares. While the degree of this attribution will also depend on participation patterns by age and Census division, the education analysis highlights both the underlying logic of the panel regression and a potential problem with it. The regression assumes that any change over time in a group's participation rate is a function of its initial occupational shares. The regression includes dummies for education, age, and Census division, but these variables enter as simple level effects and are not interacted with any time-varying variable. If the pattern of falling participation rates by education in Panel B of Figure 13 reflects the direct effects of education, rather than the effects of education working initial occupational assignment, then the results from the panel regression will be misleading.

To check whether a correlation between occupation and participation behavior is reasonable, we run a preliminary, cross-sectional regression for which this problem does not arise. For each demographic group, we calculate the average rates of participation from 1976q1 to $1979 q 4$ and from 2010q1 to 2013q4. We then run population-weighted regressions of this long-difference in participation averages on initial occupational shares as well as dummies for age, education, and Census division. If factors like age and education are the true drivers of participation rates over time - not baseline occupational shares - then this cross-sectional regression can tell us so.

Table 2 presents the results. Column 1 of Panel A runs the long-difference regression for prime-age men with only the age, education, and Census division dummies included. The constant in this regression $(-4.05)$ is therefore the expected long-run change in the participation rate for the demographic group for which all demographic dummies are omitted (25-29 year old college graduates in New England). Column 2 adds the baseline share of highskill workers. The coefficient is strongly positive (27.25), indicating that a 10-percentagepoint increase in a group's high-skill share increases the long-run change in participation by about 2.7 percentage points. Because the occupational shares must add up to one, however, groups with large high-skill shares must have either small middle-skill shares or small low-skill shares, or both. In practice, the negative correlation between high- and middle-skill shares is strongest, so entering the middle-skill baseline share in column 3 generates a large and negative coefficient while the low-skill coefficient in column 4 is small in absolute value.

These results indicate that occupational shares matter for participation even after allowing

\footnotetext{
${ }^{29}$ Autor (2010) points out a similar correlation between education levels and participation rates.
} 
for the direct effect of the demographic variables. Yet entering the occupational variables one-by-one does not really tell us which share matters. The last column enters all the baseline skill shares at the same time and drops the constant, which is required since the shares sum to one. ${ }^{30}$ Essentially, this column runs a horse race to determine the type of occupation that is most closely correlated with changes in participation over time. The middle-skill share emerges as the most robust predictor. The implication is that the high-skill share is positively correlated with participation changes in column 2 because the high-skill share is stronly and negatively correlated with the middle-skill share. Panel B of table 2 repeats the analysis with men aged 55 and older and a similar pattern emerges. We see a significant decline in labor force participation for older men likely to specialize in mid-level tasks, just as we did for prime-age men. ${ }^{31}$

\subsection{Panel regressions}

With this evidence that baseline occupational shares matter for participation in hand, we now turn to the panel regression. Even here, however, the empirical framework can be adapted so that participation rates are not forced to depend on baseline shares. Replace the high-skill/time-dummy interactions in the previous equation with a quadratic trend to get

$$
\begin{aligned}
N_{i t}= & \varphi_{1} \operatorname{Trend}_{t}+\varphi_{2} \operatorname{Trend}_{t}^{2}+\beta_{t}^{M} \cdot\left(P_{i}^{M} \times \phi_{t}\right)+\beta_{t}^{L} \cdot\left(P_{i}^{L} \times \phi_{t}\right)+ \\
& \gamma^{e} \cdot \phi_{e}+\gamma^{a} \cdot \phi^{a}+\gamma^{g} \cdot \phi_{g}+e_{i t} .
\end{aligned}
$$

Omitting the high-skill interactions to make room for the quadratic trend is informed by the results of the previous section, which indicated a small quantitative effect of baseline high-skill shares on participation changes. ${ }^{32}$

Estimating the panel regressions allows us to construct counterfactual labor-force participation rates to see how the trends in coefficients matter for overall participation rates. Results appear in Figure 14. The heavy black line in each panel is the actual participation

\footnotetext{
${ }^{30}$ The loss of the constant means that the skill-share coefficients in the last column of the table are not strictly comparable to estimates from the previous three regressions.

${ }^{31}$ The standard errors in the last column do not account for the fact that the occupational shares must sum to one. We therefore ran simulations for prime-age males in which the baseline occupational shares of the groups were drawn randomly as a triple from the empirical distribution of these shares. Doing so generates distributions of the coefficients and t-statistics under a null hypothesis that baseline occupational shares do not determine subsequent changes in participation. In these simulations, each of the occupational coefficients clusters near -4 , which is the value of the constant term in the regression without occupational shares (Column 1). Sampling without replacement across 999 repetitions, the p-values of the the actual prime-age middle-skill t-statistic was 0.028. Sampling with replacement, the p-value of the prime-age t-statistic was 0.045.

${ }^{32}$ We also performed a robustness check in which we left the high-skill interactions in the panel regression and dropped the trend. Our results below regarding the effects of baseline middle- and low-skill shares on participation changes do not change when this is done. Including a trend also allows the inclusion of seasonal dummies.
} 
rate for either prime-age men (Panel A) or older men (Panel B). The thinner solid line in each panel fixes the influence of baseline middle-skill shares to be constant throughout the sample, with this constant equal to the average of the $\beta_{t}^{M}$ interactions from 1982q1 through 1985q4. Holding constant the labor market's ability to match skills to tasks, this line therefore measures what the participation rate for prime-age men would have been if the demand for middle-skill tasks had not declined. The dashed line is constructed in a similar way by holding the effect of low-skill participation opportunities constant at the 1982-1985 average. Finally, the dash-dot line is the predicted participation rate when both the baseline middleskill and low-skill job opportunities are fixed. For this prediction, the only time-varying influence on the participation rate comes though the quadratic trend and seasonal dummies, which are also included in the regression. The striking message of Panel A is that falling demand for middle-skill tasks appears to completely explain the overall decline in labor force participation among prime-age males. The thin solid line in this graph has no downward trend, indicating that participation would have remained stable had the coefficients on the middle-skill interactions not changed. The dash-dot line holds both the low- and middle-skill opportunities constant. Again, the implied participation rate does not decline much.

These regressions offer strong evidence that polarization is related to participation. Because the regression includes a quadratic trend, a general decline among all prime-age groups could have reflected large coefficients on the trend terms and small coefficients on the baseline skill interactions. In reality, participation declines are concentrated among the groups with large baseline middle-skill shares, so the coefficients on the middle-skill interactions become increasingly large in absolute value over time. The coefficients on the trend terms are smaller, indicated by the modest bend in the dash-dot line when both the middle- and low-skill coefficients are fixed.

The lower panel of figure 14 performs the analogous experiment for older men. Declining job opportunities for middle-skill workers again have a quantitatively significant effect on male participation rates. A comparison of the thick solid line, which depicts the actual data, and the thinner solid line, which holds middle-skill effects constant, suggests that the participation rate of older males would be around eight percentage points higher had middle-skill opportunities not declined. This effect is even larger than the one registered for prime-age males. ${ }^{33}$

\footnotetext{
${ }^{33}$ Our finding of a response of nonparticipation to polarization is qualitatively consistent to Cortes et al. (2013), who use CPS data matched month-to-month to study the determinants of middle-skill employment. The authors find that in an accounting sense, changes in three flows are crucial for polarization: the rate at which unemployed workers enter middle-skill employment and the flows between nonparticipation and middle-skill employment in both directions. See also Smith (2013).
} 


\section{Conclusions}

Models of the labor market based on job search rationalize unemployment at a theoretical level and also provide specific predictions useful to policymakers. Yet they typically abstract from many features of real-world economies in order to focus attention on important features of the employment relationship, such as the structure of wage bargaining. A growing theoretical literature, extended and summarized by Blanchard and Galí (2010), seeks to embed search frictions in models with other sources of complexity, such as frictions in the setting of product prices, or in the ways in which consumers trade off consumption and leisure. This paper suggests that such extensions may be useful in understanding high-frequency employment movements at the occupational level, which are unlikely to reflect search motives alone. Much of the drop in middle-skill employment during the Great Recession is attributable to the industries that employ middle-skill workers, and thus to the product-market shocks and frictions relevant to those employers. The evidence that polarization is directly related to changes in labor-force participation suggests adding leisure to the model as well.

A formal model able to explain high-frequency movements in middle-skill employment is therefore likely to entail a fair amount of complexity. But understanding why this complexity is necessary is straightforward. Figure 15 presents education and wage data disaggregated into five industry-skill groups, including the three middle-skill groups disaggregated by industry. The chart on the left shows that since 1990, about 85 percent of high-skill workers had taken at least some college courses. ${ }^{34}$ This fraction falls to about half for middle-other workers and about one-third for middle-manufacturing and middle-construction workers. In fact, the educational makeup of these latter two groups is similar to people holding low-skill jobs; the two middle-skill groups have about the same number of less-than-high-school workers but somewhat more high-school graduates. The panel on the right graphs average real wages for the same five groups, using the wage data from the outgoing rotation groups of the CPS. ${ }^{35}$ The three middle-skill groups earn significantly more than low-skill workers and but significantly less than the high-skill group. For a middle-skill worker to move up to a highskill job, he needs more education, yet moving down to a low-skill job will probably entail a big cut in pay. Thus it is not surprising that we found middle-skill workers responding at least in part to long-run polarization trends by dropping out of the labor force altogether.

To construct an appropriate high-frequency model of middle-skill employment, we would

\footnotetext{
${ }^{34}$ That is, using the standard classifications, most high-skill workers were listed as either "some college" or "college graduates."

${ }^{35}$ Wages are defined as usual weekly earnings divided by usual weekly hours. The price deflator is the BLS's implicit price deflator for the nonfarm business sector. We have also performed a demographic adjustment so that changes in real wages for a specific group are not affected by changes in the demographic makeup of that group. Elsby, Shin, and Solon (2013) use CPS wages to construct a similar plot that is not disaggregated by occupation but shows a similar time-series pattern.
} 
need to understand how rational middle-skill workers deal with declining long-run opportunities at a cyclical frequency. What long-run and short-run factors encourage them to leave the labor force, or to be satisfied with work that pays much less than their previous jobs? How costly would it be for them to take advantage of temporarily low aggregate productivity to get more education, and how appealing would they find reallocation to home production or leisure instead? Modeling these decisions in a world of volatile labor demand and various ways to spend time while out of the labor force will be challenging.

The educational requirement of high-skill work also bears on some recent work that connects the polarization to the joblessness of recent recoveries. Jaimovich and Siu (2013) argue that large numbers of middle-skill workers, aware of long-run polarization trends, have efficiently separated during recent recessions in hopes of obtaining a high-skill job. Consistent with the previous figure, and with the results on middle-skill exits from unemployment, the Jaimovich-Siu model does not permit middle-skill workers to move directly to high-skill jobs. Middle-skill workers separating from their employers must enter a so-called switching market, which operates much like any other market in a Diamond-Mortensen-Pissarides (DMP) world. Vacancies are posted in this market and matches are made, and soon after a switching match is formed the worker obtains the skills necessary to hold a high-skill job. To reflect the long stretches of joblessness that middle-skill workers have to endure, Jaimovich and Siu (2013) posit that the exogenous vacancy-creation costs in the switching market are high. These high costs reduce the number of posted vacancies and consequently the number of switching matches, thereby forcing middle-skill workers who have left their jobs to wait a long time before becoming skilled-hence the joblessness of the recoveries. An important question for a model of this type is how well is the real-world education sector approximated by a standard DMP job market with high vacancy-posting costs. The results of this paper suggest that understanding precisely what middle-skill workers do when they leave the labor market, even temporarily, will be a key part of understanding why so many middle-skill employment relationships tend to be dissolved in recessions. 


\section{References}

Acemoglu, Daron, and David Autor. 2011. "Skills, Tasks and Technologies: Implications for Employment and Earnings." In Handbook of Labor Economics, eds. Orley Ashenfelter and David E. Card, vol. 4. Elsevier.

Autor, David H. 2010. "The Polarization of Job Opportunities in the U.S. Labor Market: Implications for Employment and Earnings." A paper jointly released by The Center for American Progress and The Hamilton Project. Available at http://economics.mit.edu/ files/5554.

Autor, David H., and David Dorn. 2013. "The Growth of Low Skill Service Jobs and the Polarization of the U.S. Labor Market." American Economic Review 103(5): 1553-1597.

Autor, David H., Lawrence F. Katz, and Melissa S. Kearney. 2008. "Trends in U.S. Wage Inequality: Revising the Revisionists." Review of Economics and Statistics 90(2): 300-323.

Autor, David H., Frank Levy, and Richard J. Murnane. 2003. "The Skill Content of Recent Technological Change: An Empirical Exploration." Quarterly Journal of Economics 118(4): 1279-1333.

Beaudry, Paul, and John DiNardo. 1991. "The Effect of Implicit Contracts on the Movement of Wages Over the Business Cycle: Evidence from Micro Data." Journal of Political Economy 99(4): 665-688.

Blanchard, Olivier J., and Jordi Galí. 2010. "Labor Markets and Monetary Policy: A New Keynesian Model with Unemployment." American Economic Journal: Macroeconomics $2(2): 1-30$.

Cortes, Guido Matais, Nir Jaimovich, Christopher J. Nekarda, and Henry E. Siu. 2013. "The Micro and Macro of Job Polarization." Available at http://www.sole-jole.org/14316.pdf.

Elsby, Michael W. L., Bart Hobijn, and Ayşegül Şahin. 2010. "The Labor Market in the Great Recession." Brookings Papers on Economic Activity 2010(1): 1-69.

Elsby, Michael W. L., Ryan Michaels, and Gary Solon. 2009. "The Ins and Outs of Cyclical Unemployment." American Economic Journal: Macroeconomics 1(1): 84-110.

Elsby, Michael W.L., Bart Hobijn, and Ayşegül Şahin. 2013. "On the Importance of the Particpation Margin for Labor Market Fluctuations." Federal Reserve Bank of San Fransisco Working Paper No. 2013-05. Available at http://www.frbsf.org/publications/economics/ papers/2013/wp2013-05.pdf. 
Elsby, Michael W.L., Donggyun Shin, and Gary Solon. 2013. "Wage Adjustment in the Great Recession." National Bureau of Economic Reseach Working Paper No. 19478. Available at http://www.nber.org/papers/w19478.

Faberman, R. Jason, and Bhashkar Mazumder. 2012. "Is There a Skills Mismatch in the Labor Market." Chicago Fed Letter No. 300, Federal Reserve Bank of Chicago. Available at http://www.chicagofed.org/digital_assets/publications/chicago_fed_ letter/2012/cfljuly2012_300.pdf.

Fujita, Shigeru, and Giuseppe Moscarini. 2013. "Recall and Unemployment." National Bureau of Economic Reseach Working Paper No. 19640. Available at http://www.nber. org/papers/w19640.

Galí, Jordi, Frank Smets, and Rafael Wouters. 2012. "Slow Recoveries: A Structural Interpretation." Journal of Money, Credit and Banking 44: 9-30.

Gertler, Mark, and Antonella Trigari. 2009. "Unemployment Fluctuations with Staggered Nash Wage Bargaining." Journal of Political Economy 117(1): 38-86.

Goldin, Claudia D., and Lawrence F. Katz. 2008. The Race Between Education and Technology. Cambridge, Mass.: Belknap Press of Harvard University Press.

Goos, Maarten, Alan Manning, and Anna Salomons. 2009. "Job Polarization in Europe." American Economic Review 99(2): 58-63.

Hagedorn, Marcus, and Iourii Manovskii. 2013. "Job Selection and Wages over the Business Cycle." American Economic Review 103(2): 771-803.

Hall, Robert E. 2005. "Employment Fluctuations with Equilibrium Wage Stickiness." American Economic Review 95(1): 50-65.

Jaimovich, Nir, and Henry E. Siu. 2013. "The Trend is the Cycle: Job Polarization and Jobless Recoveries." Duke University Working Paper. Available at https://sites.google. com/site/nirjaimovich/papers/JPJR.pdf.

Krause, Michael U., and Thomas A. Lubik. 2007. "The (Ir)relevance of Real Wage Rigidity in the New Keynesian Model with Search Frictions." Journal of Monetary Economics 54(3): $706-727$.

Manovskii, Iourii, and Gueorgui Kambourov. 2008. "Rising Occupational and Industry Mobility in the United States: 1968-1997." International Economic Review 49(1): 41-79. 
Mortensen, Dale T., and Christopher A. Pissarides. 1994. "Job Creation and Job Destruction in the Theory of Unemployment." Review of Economic Studies 61(3): 397-415.

Moscarini, Giuseppe, and Francis Vella. 2008. "Occupational Mobility and the Business Cycle." Available at http://www.econ.yale.edu/ gm76/cps_nber_wp.pdf.

Pissarides, Christopher A. 2000. Equilibrium Unemployment Theory. Second edition. Cambridge, Mass.: MIT Press.

Pissarides, Christopher A. 2009. "The Unemployment Volatility Puzzle: Is Wage Stickiness the Answer?" Econometrica 77(5): 1339-1369.

Ruggles, Steven, J. Trent Alexander, Katie Genadek, Ronald Goeken, Matthew B. Schroeder, and Matthew Sobek. 2010. Integrated Public Use Microdata Series (IPUMS): Version 5.0, [Machine-readable database]. Minneapolis: University of Minnesota.

Shimer, Robert. 2005. "The Cyclical Behavior of Equilibrium Unemployment and Vacancies." American Economic Review 95(1): 25-49.

Shimer, Robert. 2012. "Reassessing the Ins and Outs of Unemployment." Review of Economic Dynamics 15(2): 127-148.

Smith, Christopher L. 2013. "The Dynamics of Labor Market Polarization." Federal Reserve Board of Governors, Finance and Economics Discussion Series Paper 2013-57. Available at http://www.federalreserve.gov/pubs/feds/2013/201357/201357abs.html.

Stock, James H., and Mark W. Watson. 2011. "Dynamic Factor Models." In Oxford Handbook of Economic Forecasting, eds. Michael P. Clements and David F. Hendry. Oxford, U.K.: Oxford University Press.

Stock, James H., and Mark W. Watson. 2012. "Disentangling the Channels of the 2007-2009 Recession." Princeton University Working Paper. Available at http://www.princeton.edu/ $\sim$ mwatson/papers/Stock_Watson_Disentangling_May_2012.pdf.

Tüzemen, Didem, and Jonathan Willis. 2013. "The Vanishing Middle: Job Polarization and Workers' Response to the Decline in Middle-Skill Jobs." Federal Reserve Bank of Kansas City Economic Review 5-32. First Quarter. 
Panel A: Employment Shares for Occupational Groups from Decadal Census Data
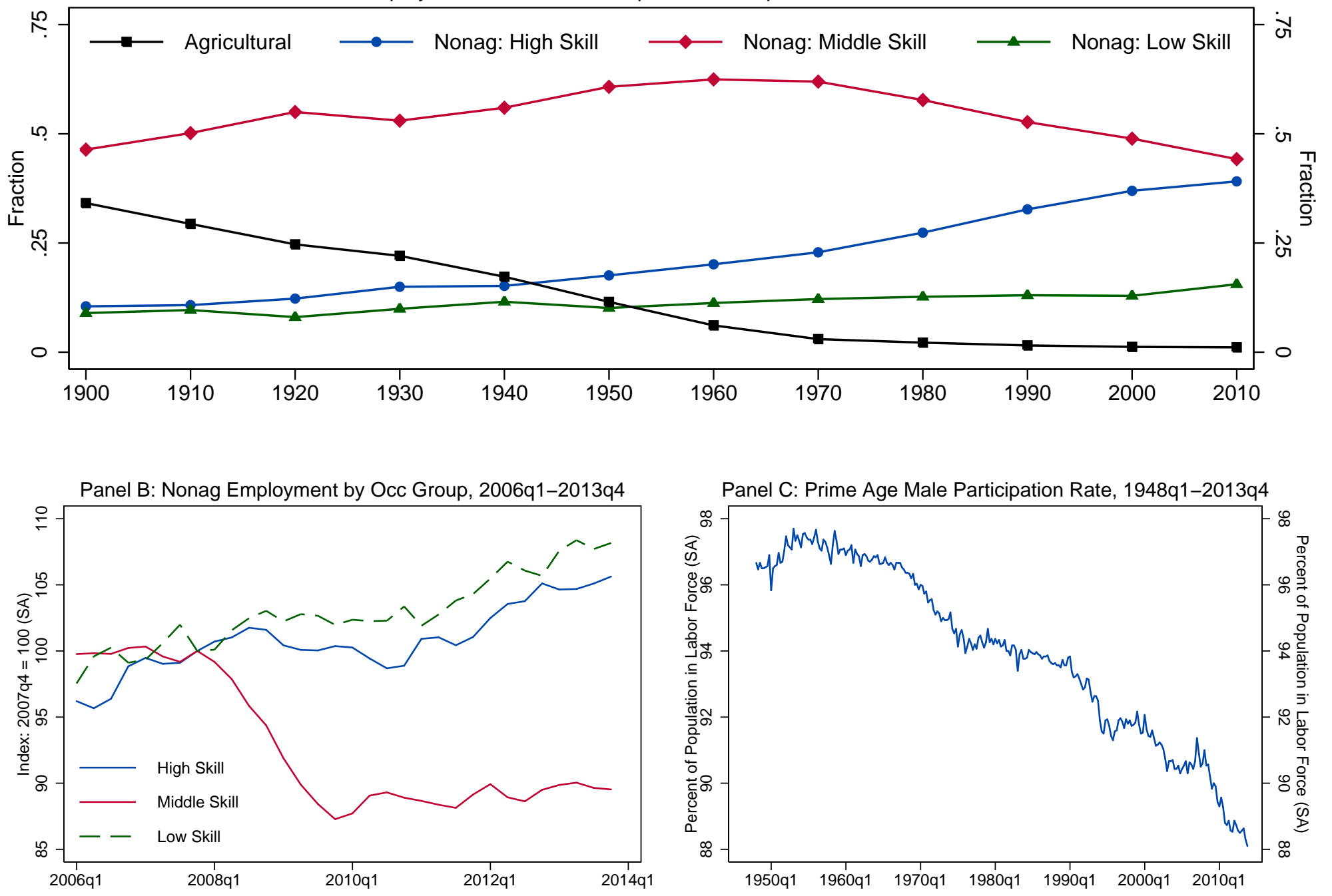

Figure 1. Long-Run Occupational Shares, Short-Run Employment Movements, And Labor-Force Participation. Note: Occupational shares are from IPUMS (Ruggles et al. 2010). 


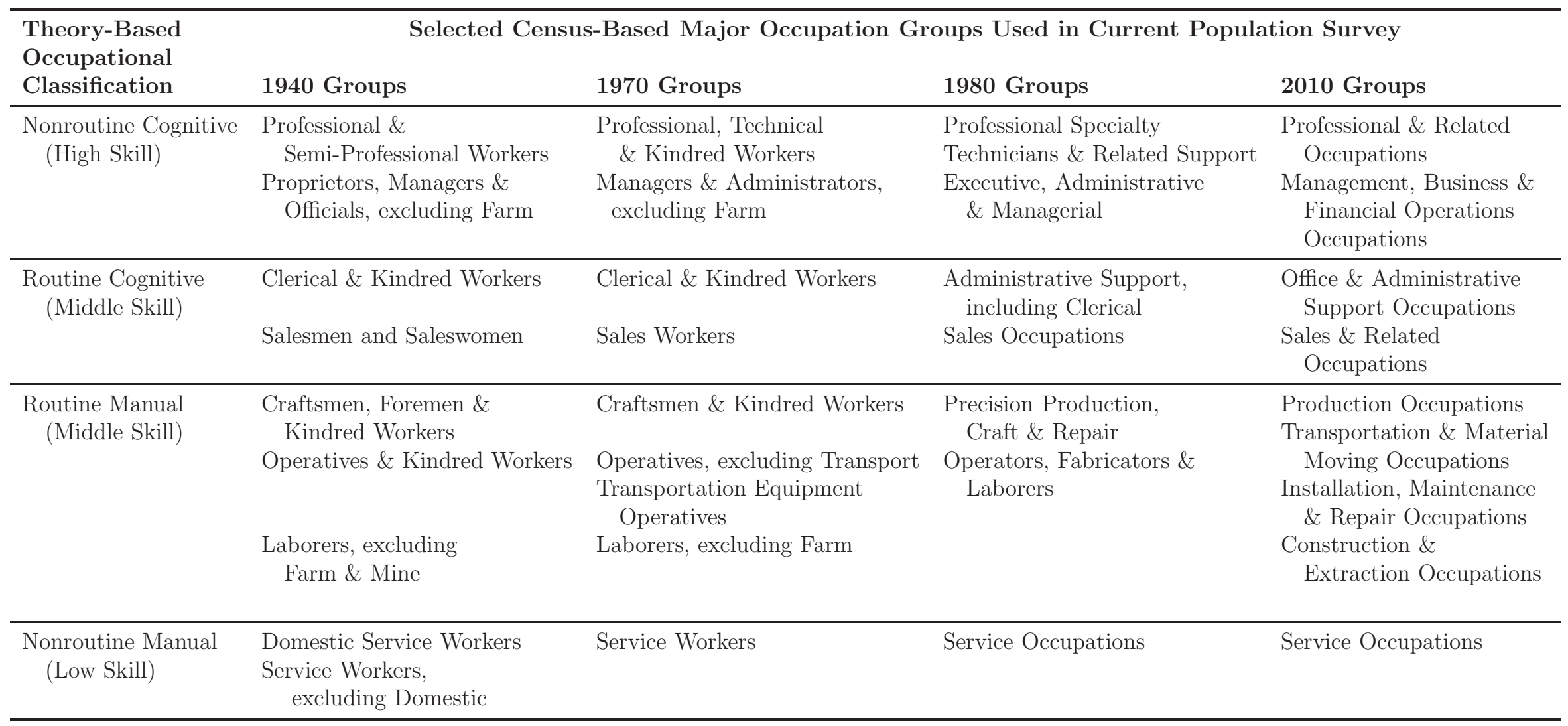

Table 1. Consistent Occupational Groups in the Current Population Survey. Note: The four theory-based occupational classifications were originally suggested by Jaimovich and Siu (2013). 
Panel A: Manufacturing Share

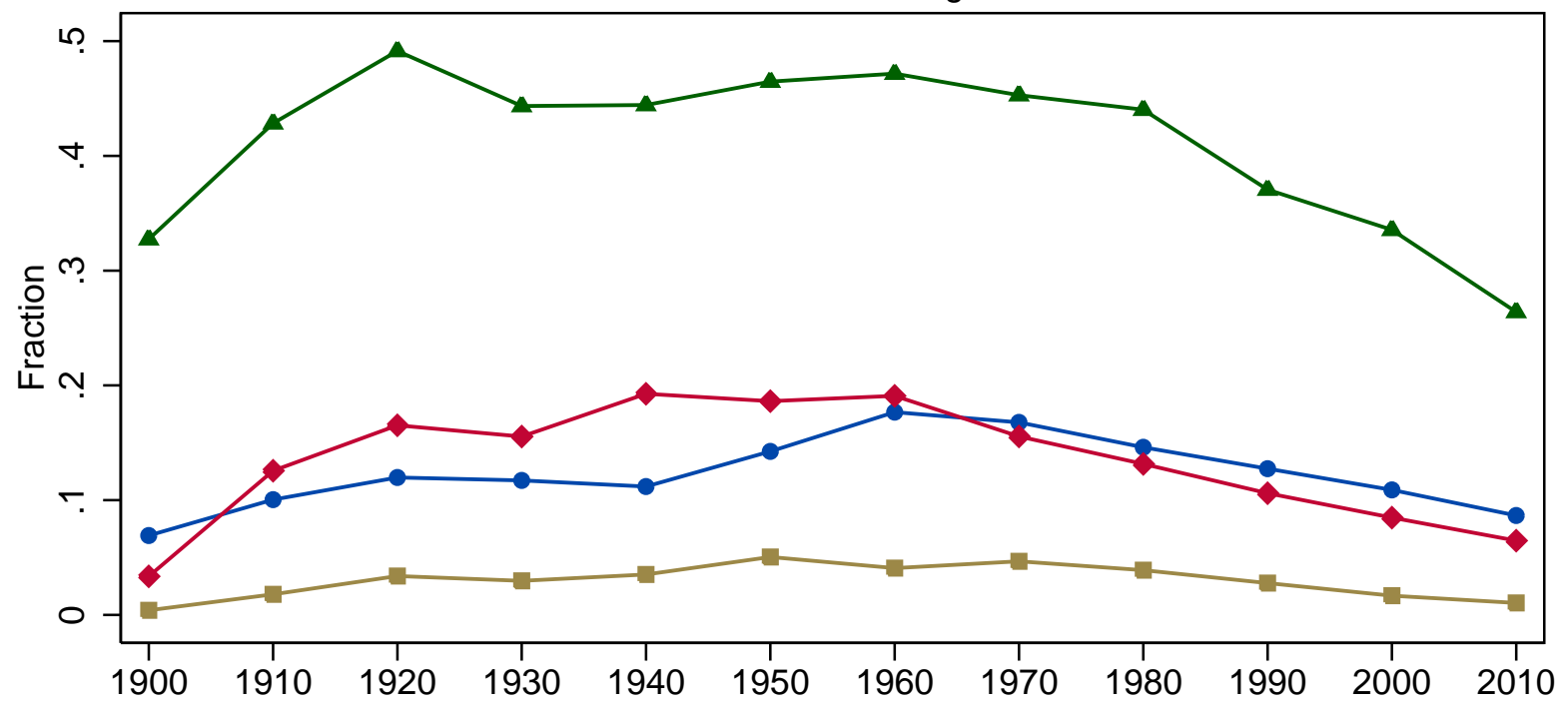

Panel B: Construction Share
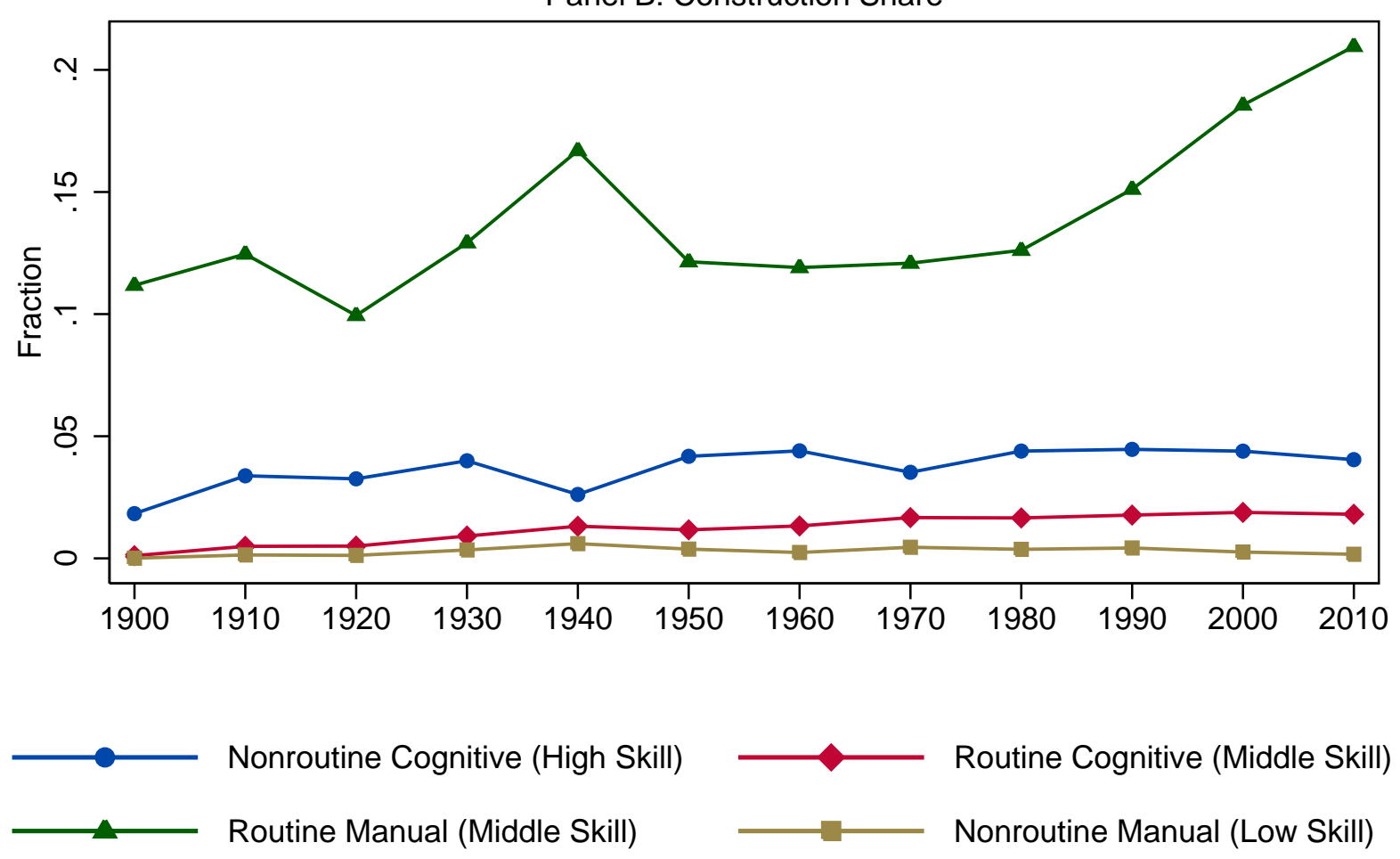

Figure 2. Manufacturing and Construction Shares in Four Occupational Classifications. Source: Ruggles et al. (2010). 

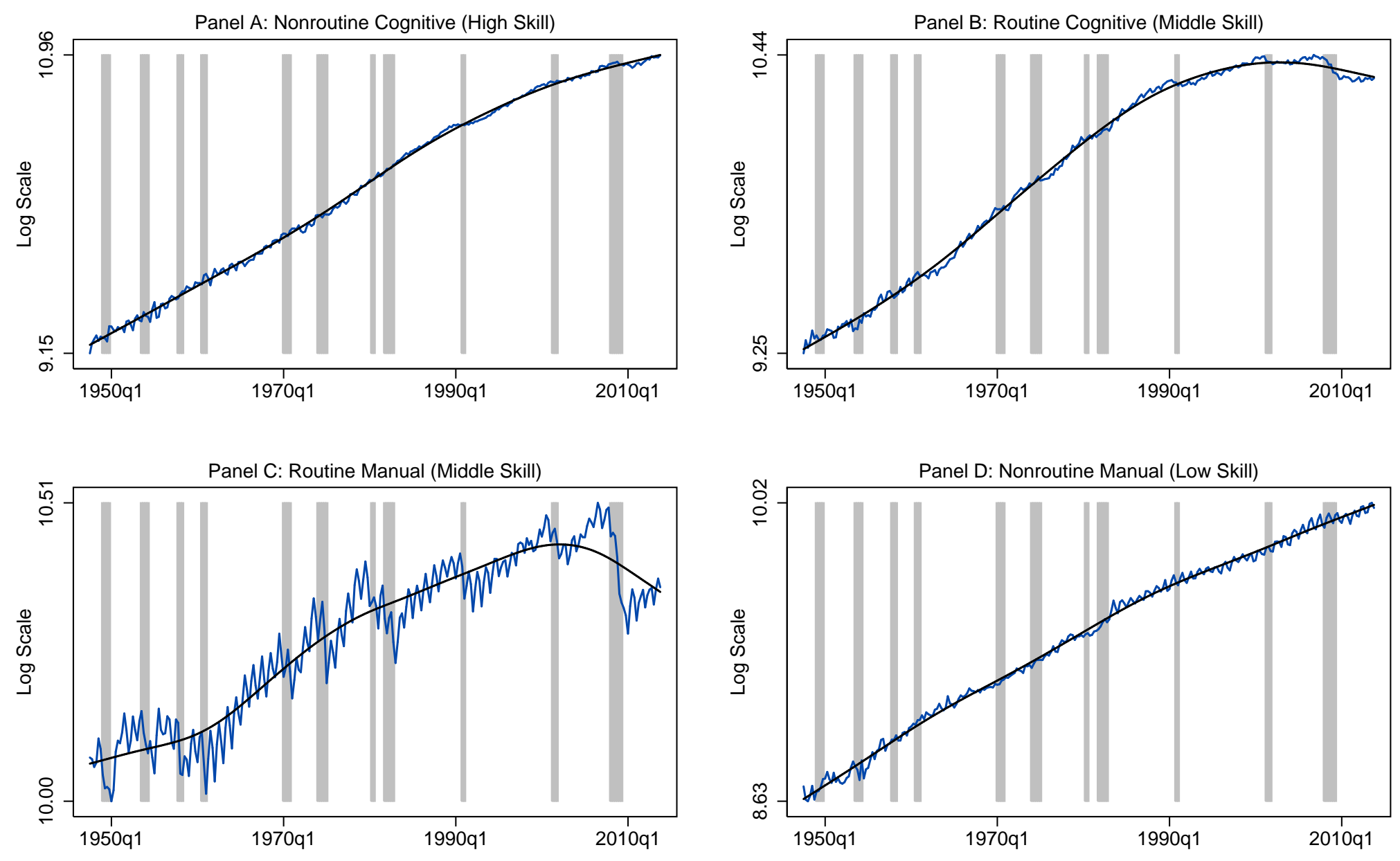

Figure 3. Employment for Four OCCUPATIONS: 1947Q3-2013Q4: Log LEVELS AND HP tRends $(\lambda=100,000)$. 


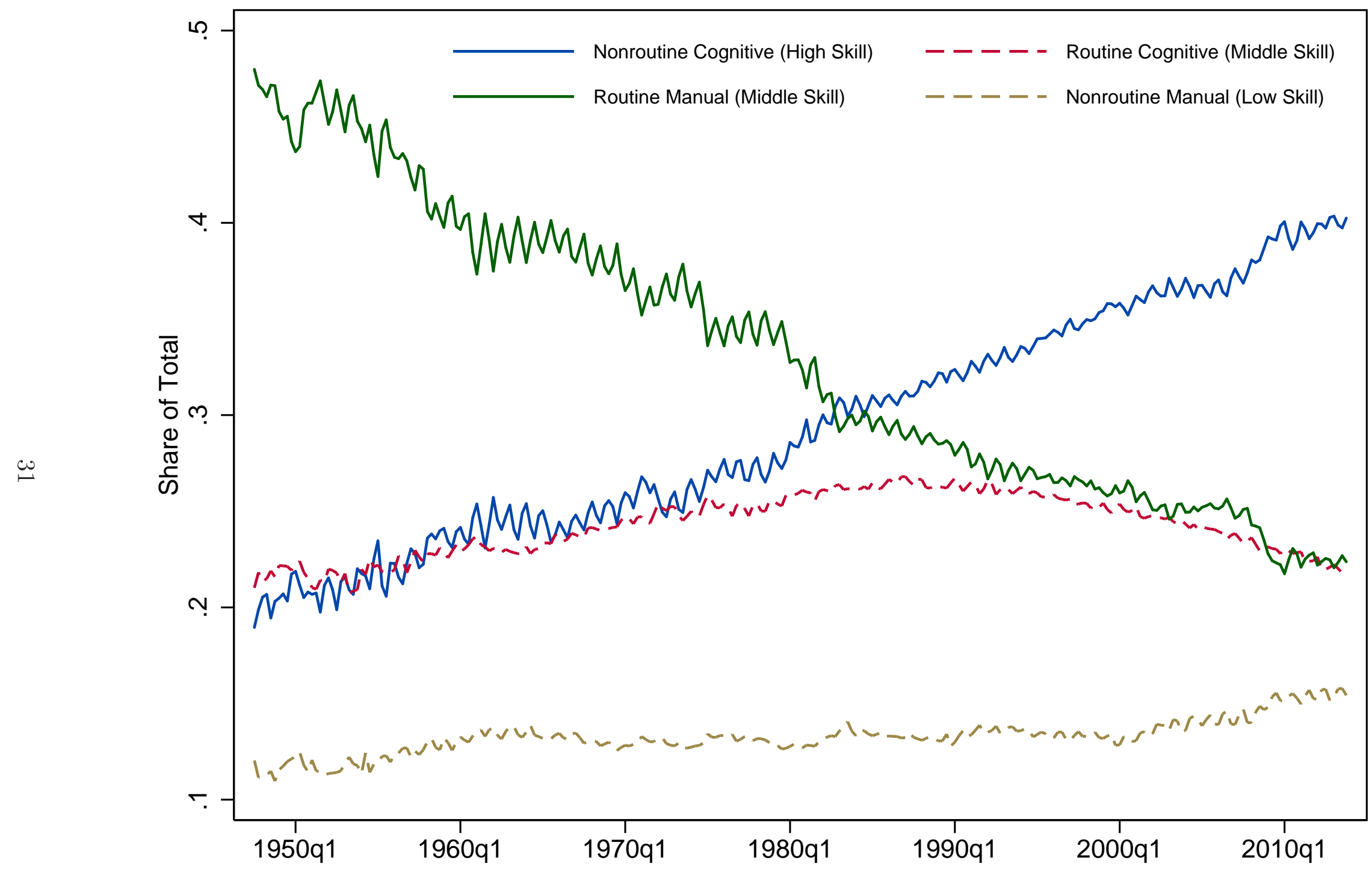

Figure 4. Shares of Employment for Four Occupational Groups: 1947Q3-2013q4. 

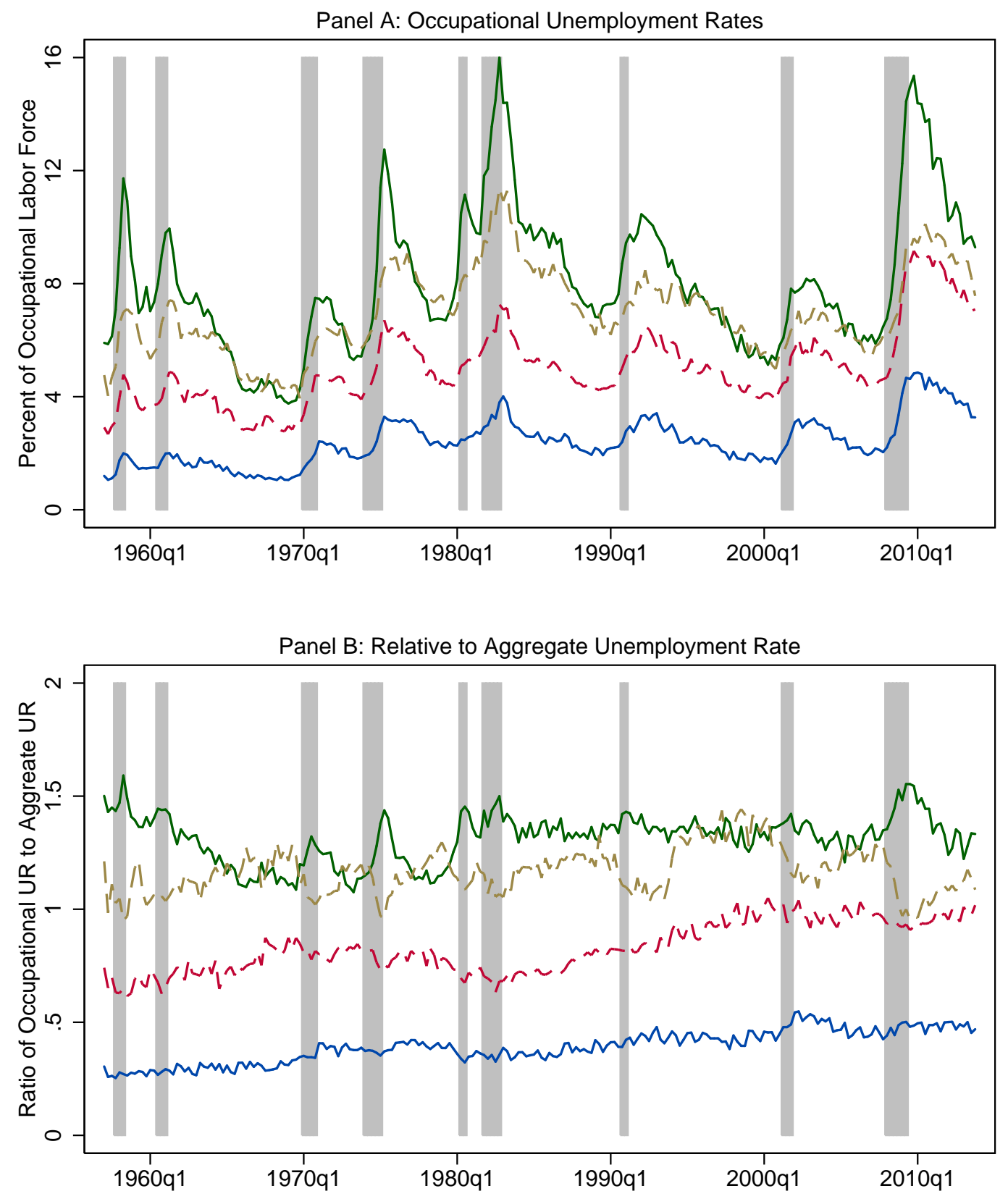

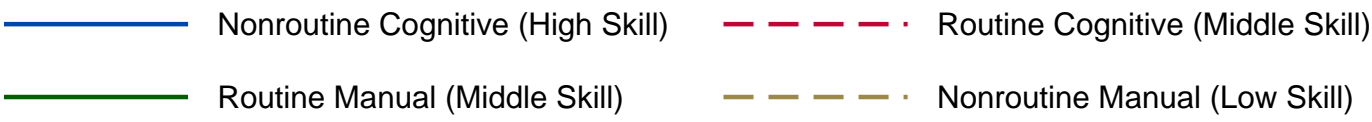

Figure 5. Consistent Unemployment Rates: 1957Q1-2013Q4. 

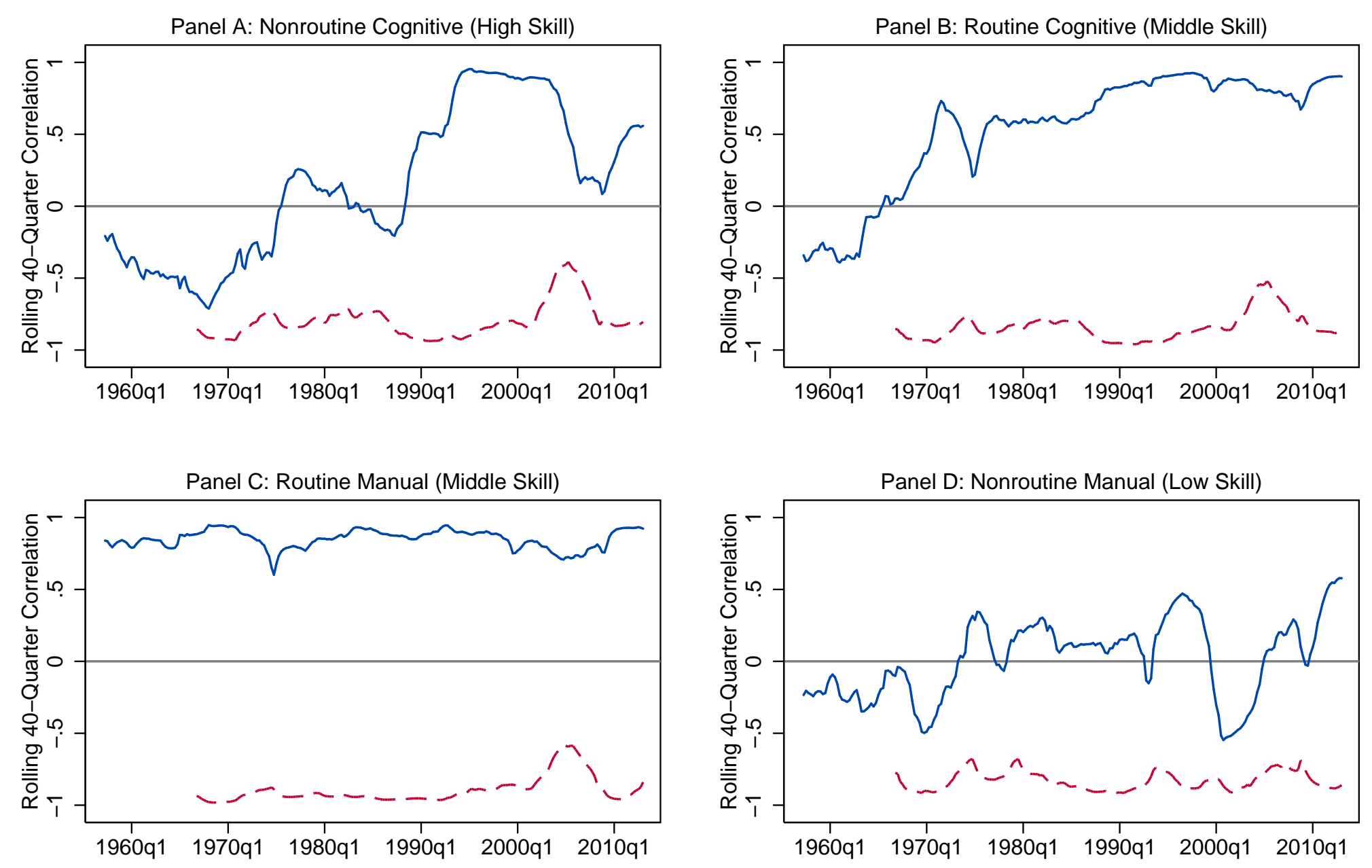

GDP Correlation with Employment Level

- - - - GDP Correlation with Unemployment Rate

Figure 6. Rolling Correlations among Occupation-Specific Employment Levels and Unemployment Rates and Real GDP. 
Panel A: 1990-91 Recession
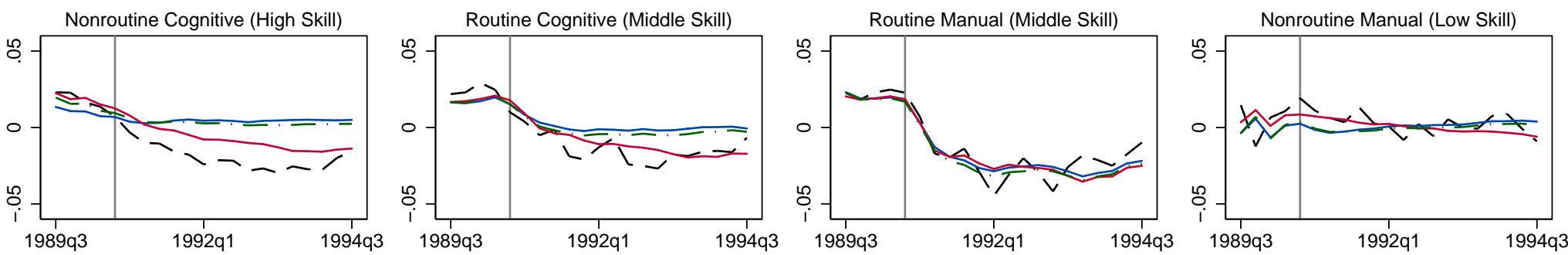

Panel B: 2001 Recession
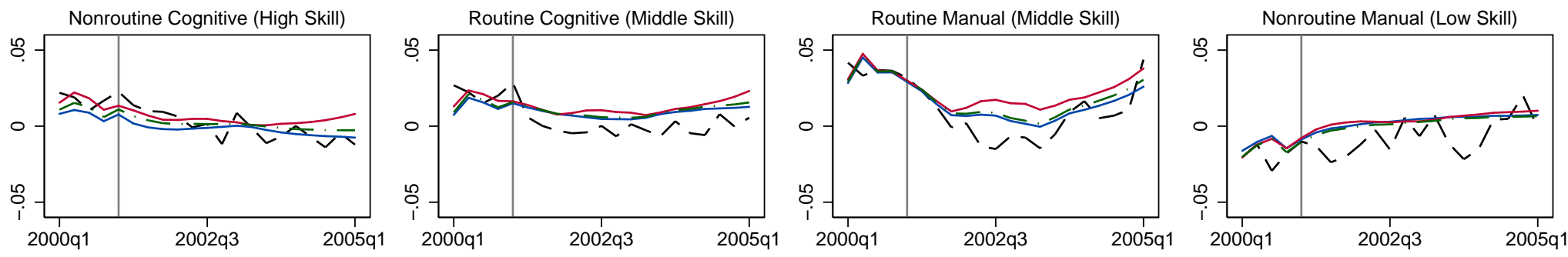

Panel C: 2008-09 Recession
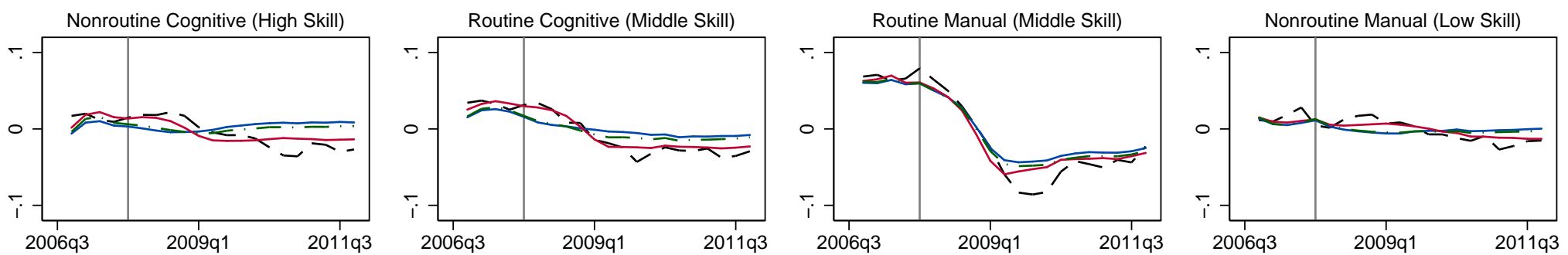

- - - - Actua

\section{Dynamic Forecast: Early Model (1947q3-1985q4)}

Dynamic Forecast: Later Model (1986q1-2013q4)

- $\cdot$ - $\cdot$ - Dynamic Forecast: Full-Sample Model

Figure 7. Dynamic Forecasts from Levels-Based Dynamic Factor Model. 

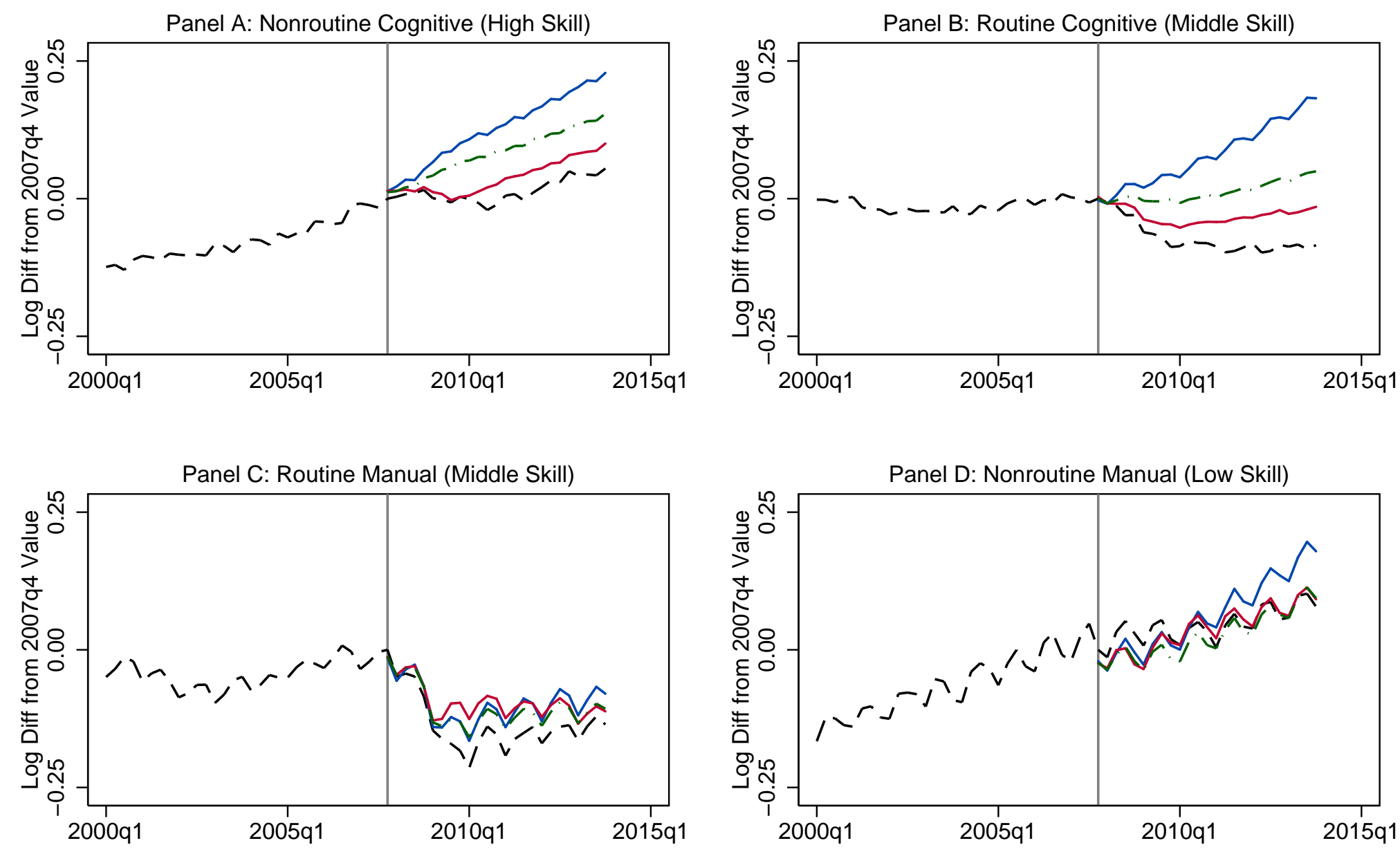

---- Actual

Dynamic Forecast: 1947q3-1985q4 Model

Dynamic Forecast: 1986q1-2007q3 Model

- - - - - - Dynamic Forecast: Full-Sample (through 2007q3)

Figure 8. Dynamic Forecasts from Differenced Model of Occupational Employment Growth. 

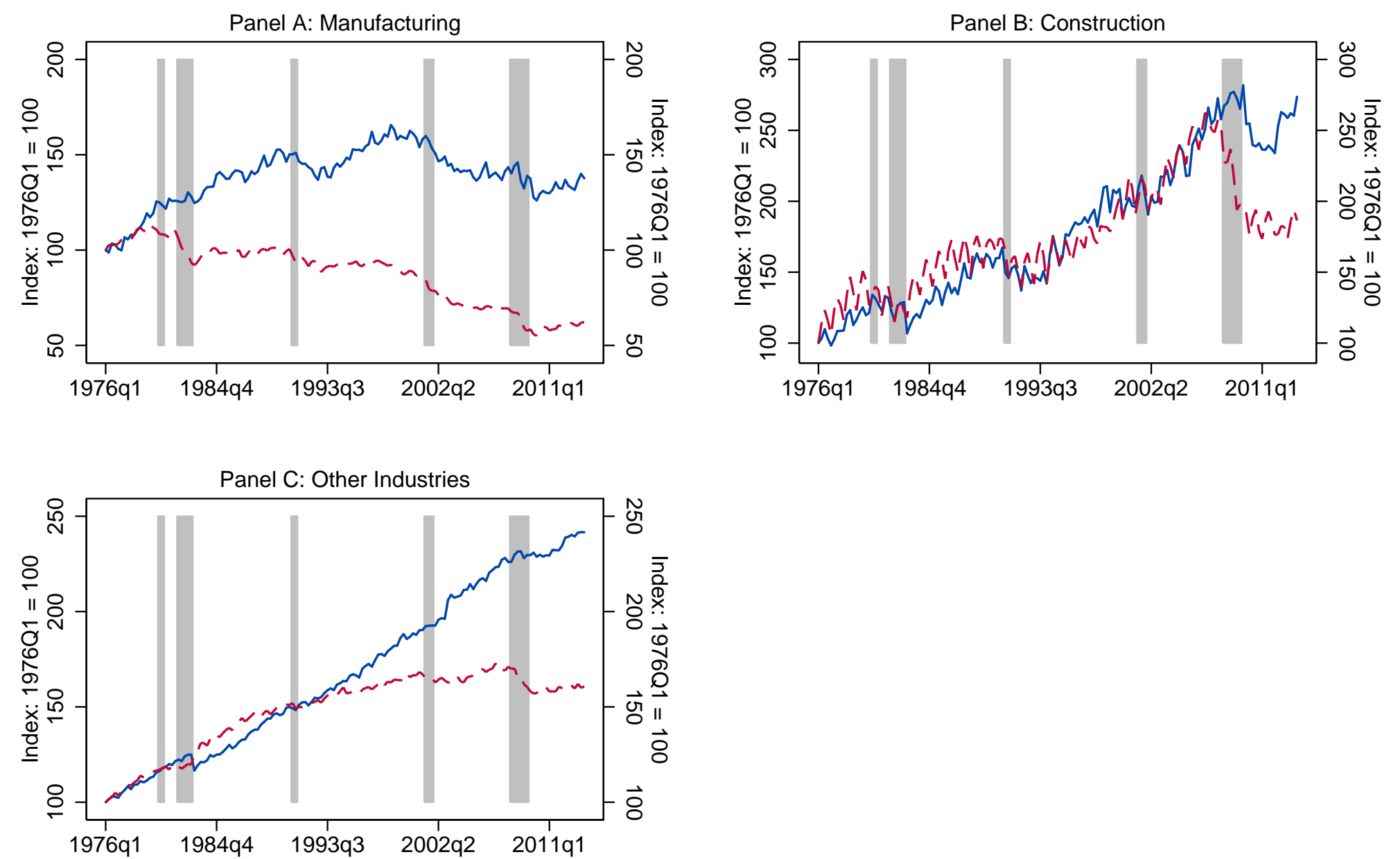

Nonroutine (High and Low Skill) $\quad-\quad--\cdots$ Routine (Middle Skill)

Figure 9. Employment Growth by Occupational Group and Industry. 


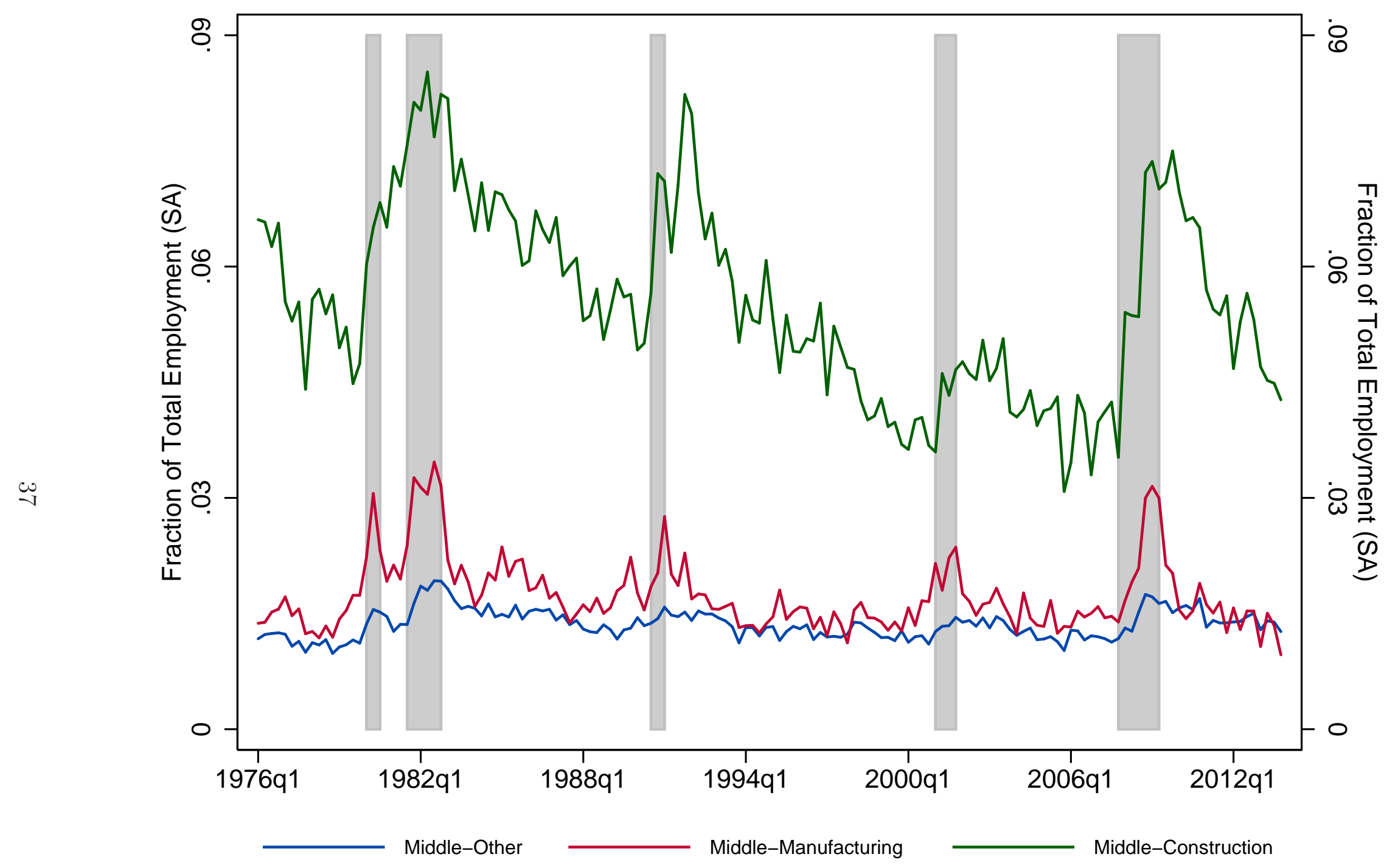

Figure 10. Flows from Employment to Unemployment (EU) for Middle-Skill Workers in Three Industry Groups. Note: Flows hold constant the demographic makeup of the occupational group and also correct for time-aggregation. 
Panel A: EE Flows (1994-2013)
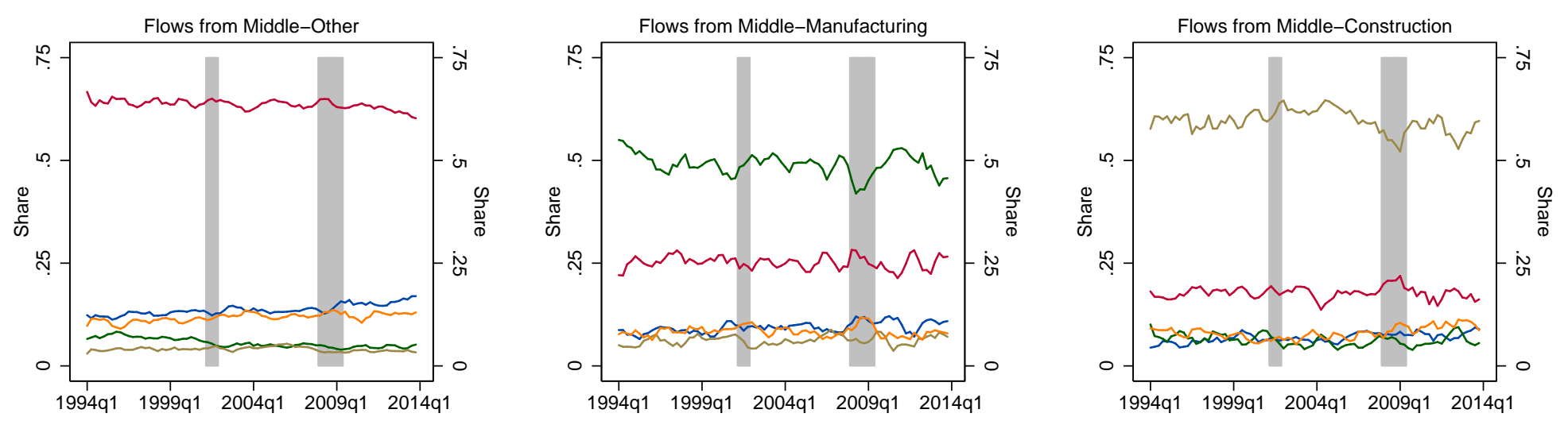

Panel B: UE Flows (1976-2013)
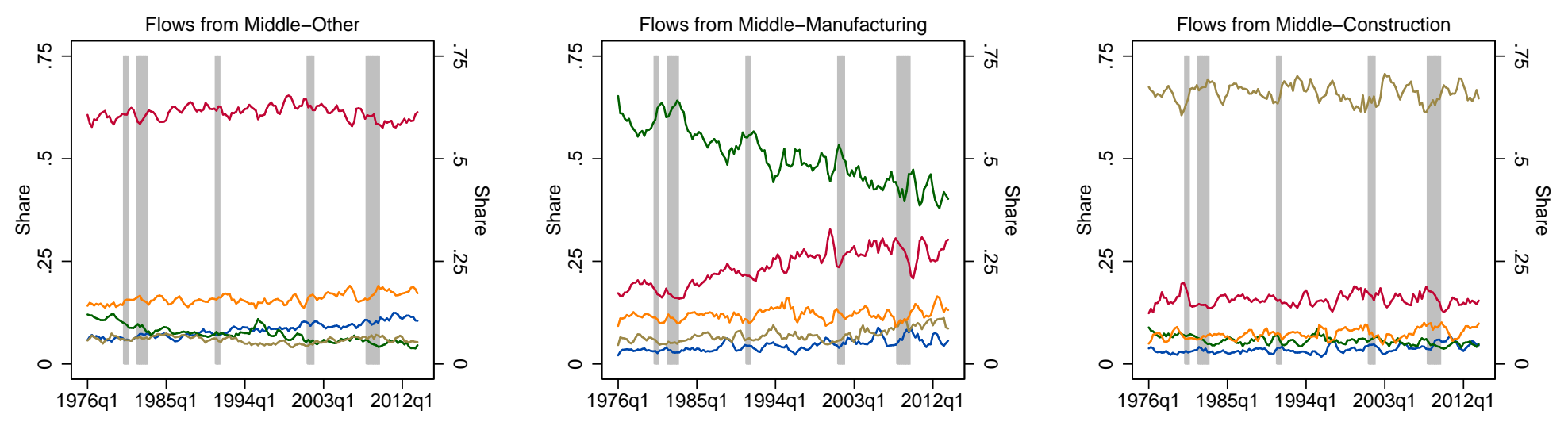

Figure 11. Destinations for Flows from Employment-to-Employment (EE) And Unemployment-to-Employment (UE) For MiddleSkill Workers in Three Industry Groups. 

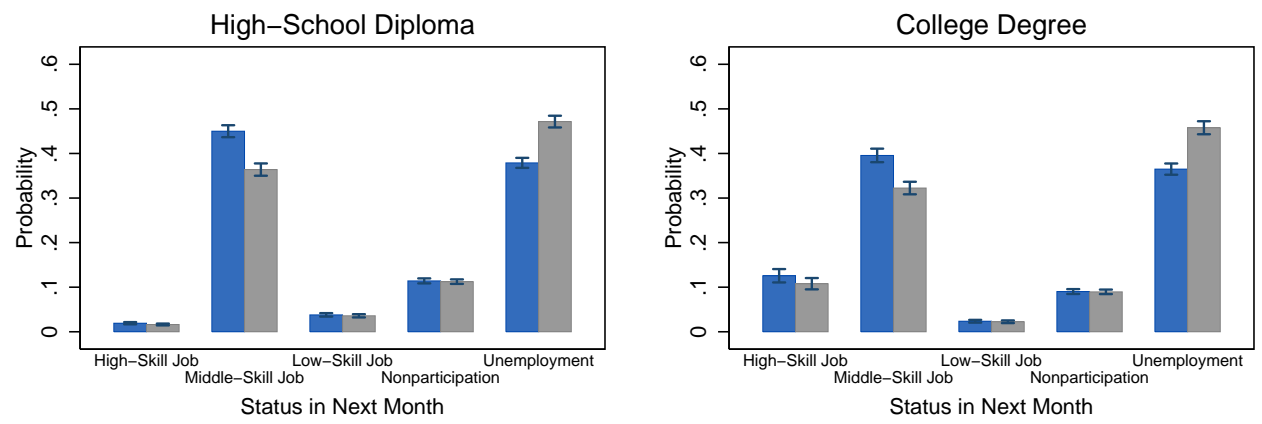

Panel B: Middle-Manufacturing Unemployed
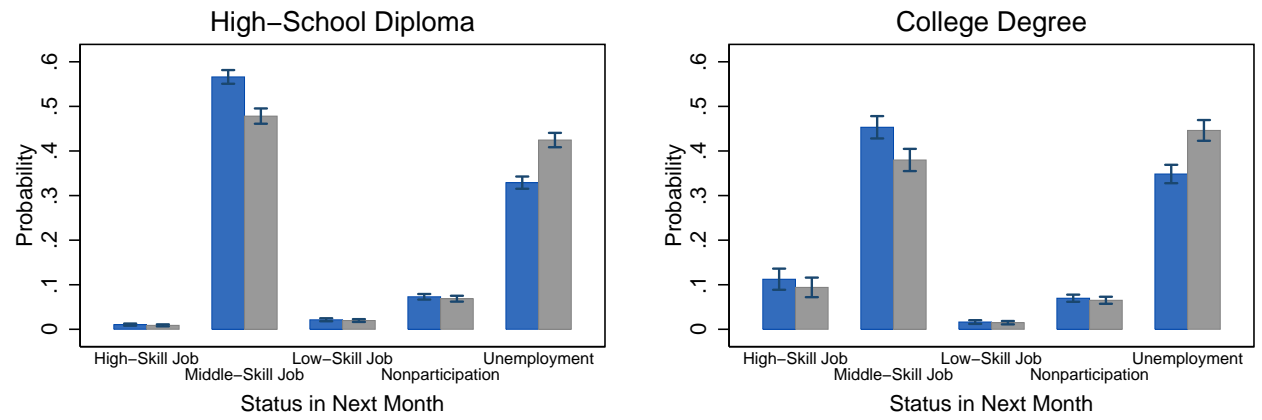

Panel C: Middle-Construction Unemployed
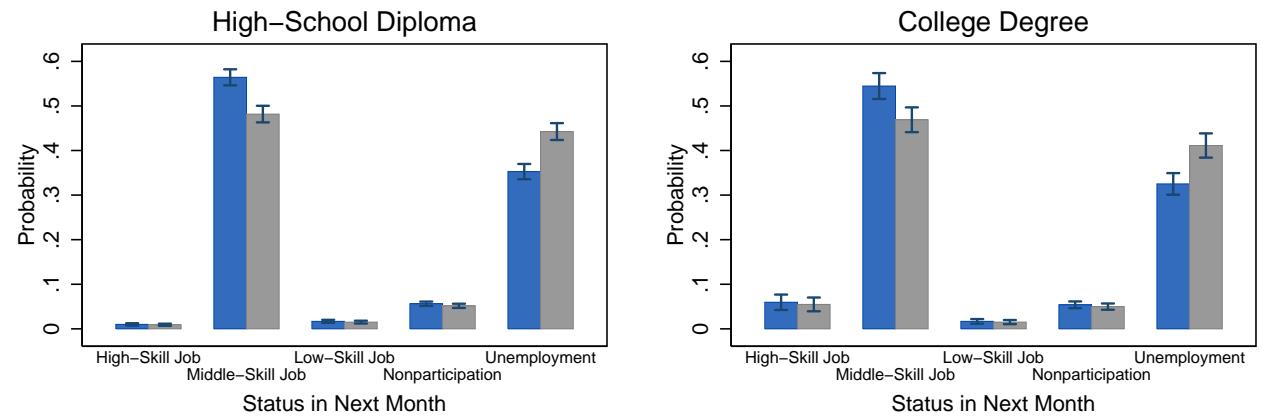

High Job-Finding Rate (One Std. Dev. Above Mean)

Low Job-Finding Rate (One Std. Dev. Below Mean)

Figure 12. Transition Probabilities for Baseline Unemployed Middle-Skill Workers. Note: Each panel represents predicted probabilities from a separate multinomial logit model of unemployment transitions. Regressors include demographic and duration dummies defined so that the baseline worker is an unmarried, white, 35-year-old male with zero to one weeks of unemployment duration and either a high-school diploma (left graphs) or a college degree (right graphs). Regressors also include an aggregate "job-finding" rate. This rate is the common factor generated by a system of five average unemployment-to-employment (UE) rates generated by the three middle-skill groups and high- and low-skill workers. Confidence bands are 95 percent intervals based on standard errors clustered by quarter. 
Panel A: 1976-81 Occupational Shares by Educational Attainment and Age, New England Males
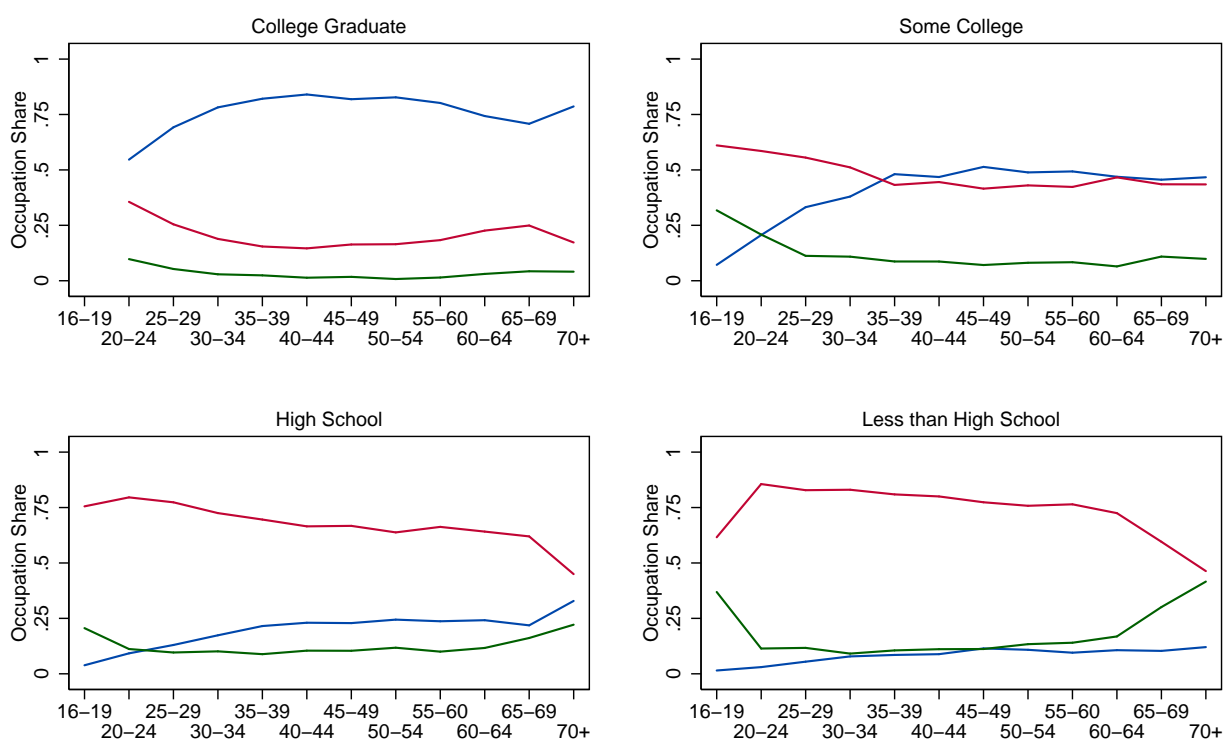

High Skill

Middle Skill

Low Skill

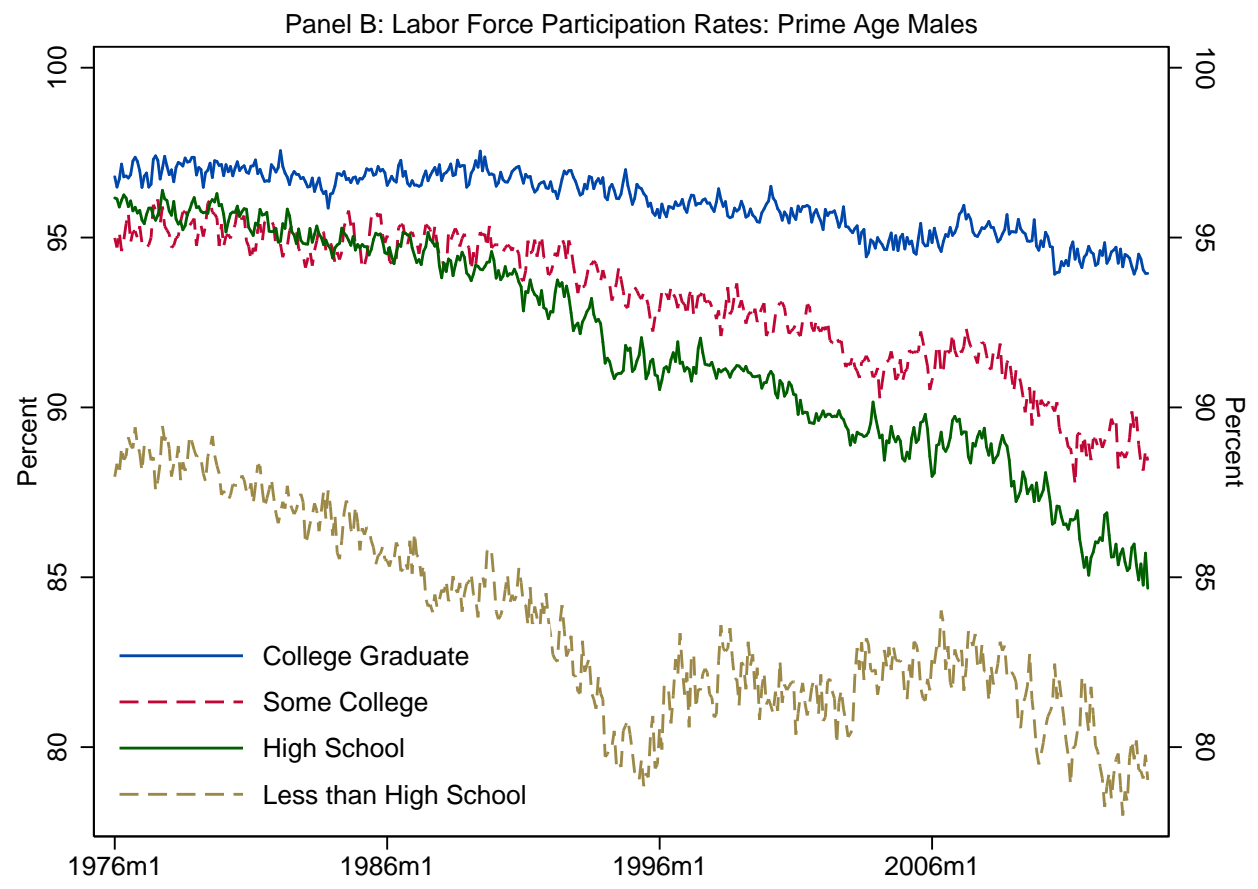

Figure 13. Baseline Occupational Shares and labor Force Participation Rates for Men. 


\begin{tabular}{|c|c|c|c|c|c|}
\hline \multicolumn{6}{|c|}{ Panel A: Prime Age (Ages 25-54) } \\
\hline \multirow[b]{2}{*}{ High-Skill Share } & (1) & $(2)$ & (3) & (4) & $(5)$ \\
\hline & \multicolumn{3}{|c|}{$\begin{array}{l}27.25^{* * *} \\
(6.89)\end{array}$} & & $\begin{array}{l}3.76 \\
(2.07)\end{array}$ \\
\hline Middle-Skill Share & & \multicolumn{3}{|c|}{$\begin{array}{c}-26.16^{* * *} \\
(6.58)\end{array}$} & $\begin{array}{c}-25.10^{* * *} \\
(5.25)\end{array}$ \\
\hline Low-Skill Share & & & & $\begin{array}{c}4.63 \\
(15.31)\end{array}$ & $\begin{array}{c}-10.50 \\
(14.42)\end{array}$ \\
\hline Constant & $\begin{array}{c}-4.05^{* * *} \\
(0.81)\end{array}$ & $\begin{array}{c}-23.31^{* * *} \\
(5.10)\end{array}$ & $\begin{array}{c}2.45 \\
(1.69)\end{array}$ & $\begin{array}{c}-4.26^{* * *} \\
(1.04)\end{array}$ & \\
\hline Observations & 216 & 216 & 216 & 216 & 216 \\
\hline \multicolumn{6}{|c|}{$\begin{array}{l}\text { Panel B: Older Males (Ages } 5 \mathbf{5}+\text { ) } \\
\text { (1) }\end{array}$} \\
\hline High-Skill Share & & $\begin{array}{c}36.89^{* * *} \\
(10.10)\end{array}$ & & & $\begin{array}{c}2.94 \\
(2.59)\end{array}$ \\
\hline Middle-Skill Share & & & $\begin{array}{c}-34.36^{* * *} \\
(7.51)\end{array}$ & & $\begin{array}{c}-25.65^{* * *} \\
(7.61)\end{array}$ \\
\hline Low-Skill Share & & & & $\begin{array}{l}47.04^{* * *} \\
(13.69)\end{array}$ & $\begin{array}{c}14.96 \\
(16.02)\end{array}$ \\
\hline Constant & $\begin{array}{c}-4.60^{* * *} \\
(1.35)\end{array}$ & $\begin{array}{c}-32.08^{* * *} \\
(7.89)\end{array}$ & $\begin{array}{c}4.37^{*} \\
(1.96)\end{array}$ & $\begin{array}{l}-4.31^{* * *} \\
(1.10)\end{array}$ & \\
\hline Observations & 144 & 144 & 144 & 144 & 144 \\
\hline
\end{tabular}

Table 2. Long-Difference Regressions of Labor-Force Participation Rates for Male DemoGraphic Groups, 2010Q1-2013q4 Average Relative to 1976q1-1979Q4 Average. Note: ${ }^{*} p<0.05$, ${ }^{* *} p<0.01,{ }^{* * *} p<0.001$. Robust (White) standard errors in parentheses. Occupational shares correspond to average employment by skill class from the 1976q1-1981q4 period. Age, education, and Census division dummies are included in all regressions. The constant is dropped in column 5. 

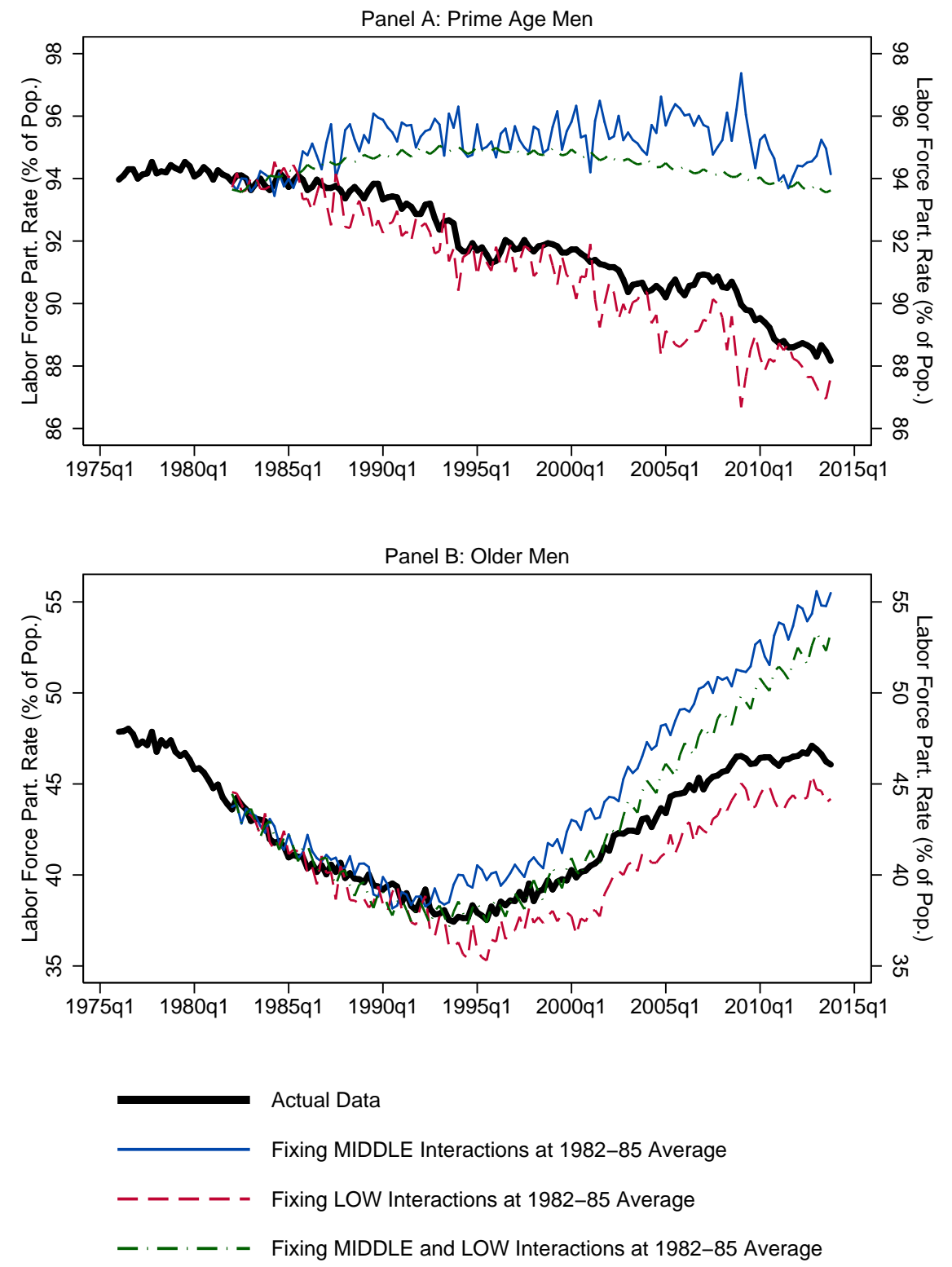

Figure 14. Counterfactual Labor Force Participation Rates for Men. Note: For counterfactual participation rates, coefficient estimates on skill-time interactions in the regression model are held constant at their average 1982-1985 values. 


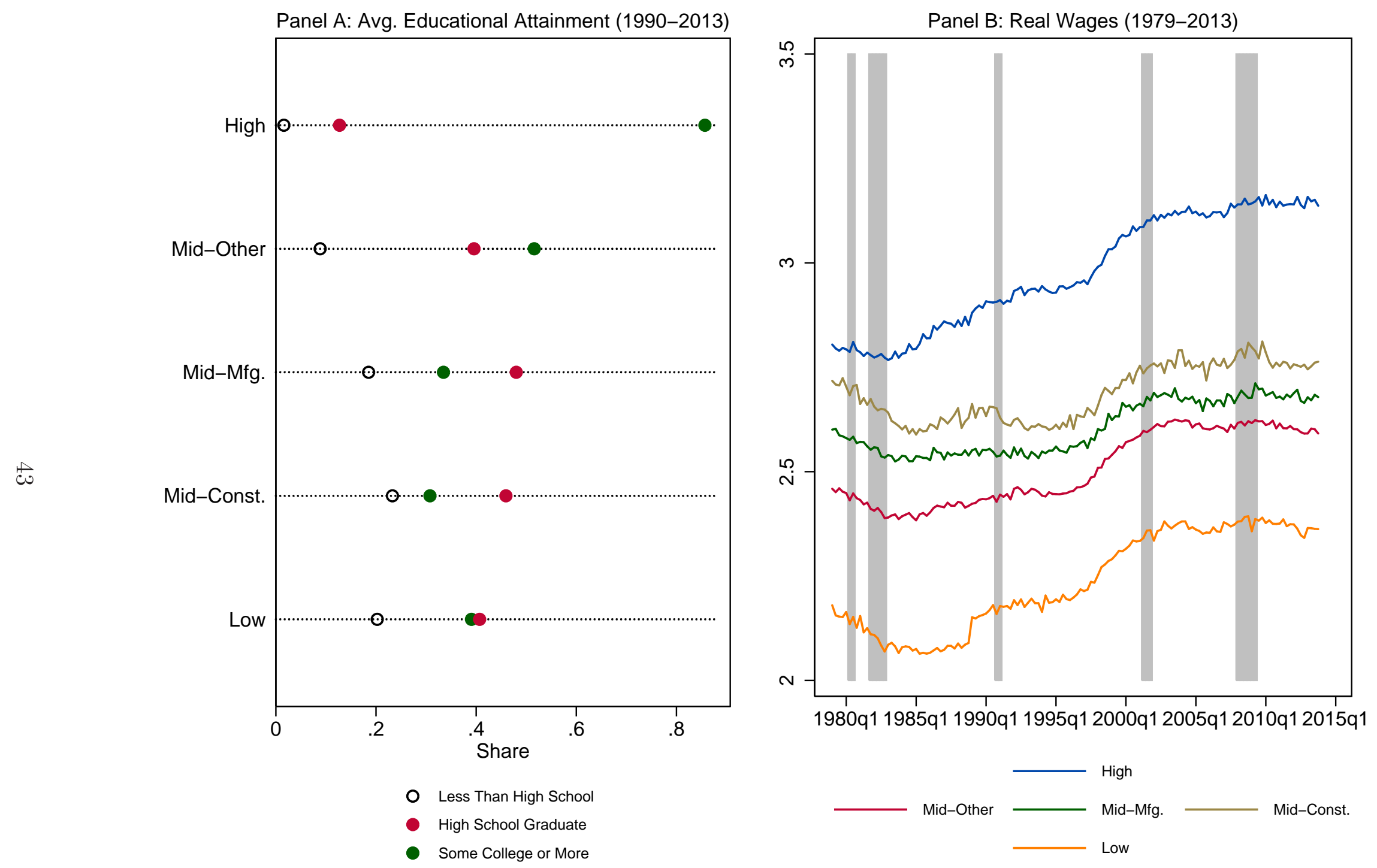

Figure 15. Educational Attainment and Real Wages for Five Industry-Occupation Groups. 